Supporting Information

\title{
Optimizing Potable Water Reuse Systems: Chloramines or Hydrogen Peroxide for UV-based Advanced Oxidation Process?
}

\author{
Kiranmayi P. Mangalgiri ${ }^{1}$, Samuel Patton ${ }^{1,2}$, Liang $\mathrm{Wu}^{1,2}$, Shanhui $X u^{l}$, \\ Kenneth P. Ishida ${ }^{3}$,Haizhou Liu ${ }^{1,2} *$ \\ ${ }^{1}$ Department of Chemical and Environmental Engineering, University of California, Riverside, CA \\ 92521 \\ ${ }^{2}$ Program of Environmental Toxicology, University of California, Riverside, CA 92521 \\ ${ }^{3}$ Research \& Development Department, Orange County Water District, Fountain Valley, CA 92708 \\ * Corresponding author, Tel: (951) 827-2076; Fax: (951) 827-5696; \\ Email: haizhou@engr.ucr.edu
}

\section{This PDF file includes:}

Pages: 46

Supporting text $\mathrm{S} 1$ to $\mathrm{S} 7$

Figures $\mathrm{S} 1$ to $\mathrm{S} 17$

Tables S1 to S2

References for supplemental information section

Submitted to Environmental Science \& Technology 


\section{TABLE OF CONTENTS}

Text S1. Competition kinetic method for the quantification of radical steady-state concentrations. ...4

Figure S1. Degradation of benzoate in pilot reactor showing the contribution of $\mathrm{HO}^{\circ}, \mathrm{Cl}^{\circ}$, and other radical species in degradation at different doses of $\mathrm{H}_{2} \mathrm{O}_{2}$

Text S2. Details on analytical methods 10

Table S1. Average water quality of reverse osmosis permeate over experimentation period. 13

Text S3. Details on pilot-scale UV oxidation experiments . 14

Figure S2. A schematic illustration of the pilot-scale experimental setup. .17

Text S4. UV-AOP bench-scale experimental set up.

Figure S3. Bar chart showing the log removal of 1,4-D in OCWD pilot-scale reactor, described in Text S3, and bench-scale reactor.

Table S2. Second-order rate constants for the reaction of relevant radicals with trace organic compounds in this study.

Figure S4. Pilot-scale reactor data showing the effect of $\mathrm{H}_{2} \mathrm{O}_{2}$ and $\mathrm{NH}_{2} \mathrm{Cl}$ concentration on the $\log$ removal of trace organic contaminants (a) ATN, (b) DEET, and (c) TCE from RO permeate.

Text S5. Calculations of branching ratio of $\mathrm{HO}^{\bullet}$ and RCS for all indicator contaminants

Figure S5. Branching ratio of $\mathrm{HO}^{\circ}$ and $\mathrm{Cl}^{\circ}$ in the removal of $\mathrm{ATN}$ by $\mathrm{UV}-\mathrm{H}_{2} \mathrm{O}_{2}-\mathrm{NH}_{2} \mathrm{Cl}$ AOP in for three doses of $\mathrm{H}_{2} \mathrm{O}_{2}$, (a,d) $0 \mathrm{mg} \mathrm{L}^{-1}$, (b,e) $2.5 \mathrm{mg} \mathrm{L}^{-1}$, and (c,f) $5 \mathrm{mg} \mathrm{L}^{-1}$.

Figure S6. Branching ratio of $\mathrm{HO}^{\circ}$ and $\mathrm{Cl}^{\circ}$ in the removal of $\mathrm{CAF}$ by $\mathrm{UV}-\mathrm{H}_{2} \mathrm{O}_{2}-\mathrm{NH}_{2} \mathrm{Cl} \mathrm{AOP}$ in for three doses of $\mathrm{H}_{2} \mathrm{O}_{2}$, (a,d) $0 \mathrm{mg} \mathrm{L}^{-1}$, (b,e) $2.5 \mathrm{mg} \mathrm{L}^{-1}$, and (c,f) $5 \mathrm{mg} \mathrm{L}^{-1}$..

Figure S7. Branching ratio of $\mathrm{HO}^{\circ}$ and $\mathrm{Cl}^{\bullet}$ in the removal of DEET by $\mathrm{UV}-\mathrm{H}_{2} \mathrm{O}_{2}-\mathrm{NH}_{2} \mathrm{Cl} \mathrm{AOP}$ in for three doses of $\mathrm{H}_{2} \mathrm{O}_{2}$, (a,d) $0 \mathrm{mg} \mathrm{L}^{-1}$, (b,e) $2.5 \mathrm{mg} \mathrm{L}^{-1}$, and (c,f) $5 \mathrm{mg} \mathrm{L}^{-1}$..

Figure S8. Branching ratio of $\mathrm{HO}^{\circ}$ and $\mathrm{Cl}_{2}{ }^{-}$in the removal of TCE by $\mathrm{UV}-\mathrm{H}_{2} \mathrm{O}_{2}-\mathrm{NH}_{2} \mathrm{Cl} \mathrm{AOP}$ in for three doses of $\mathrm{H}_{2} \mathrm{O}_{2}$, (a,d) $0 \mathrm{mg} \mathrm{L}^{-1}$, (b,e) $2.5 \mathrm{mg} \mathrm{L}^{-1}$, and (c,f) $5 \mathrm{mg} \mathrm{L}^{-1}$.

Figure S9. Branching ratio of $\mathrm{HO}^{\circ}$ and $\mathrm{Cl}_{2}{ }^{-}$in the removal of 1,4-D by $\mathrm{UV}-\mathrm{H}_{2} \mathrm{O}_{2}-\mathrm{NH}_{2} \mathrm{Cl}$ AOP in for three doses of $\mathrm{H}_{2} \mathrm{O}_{2}$, (a,d) $0 \mathrm{mg} \mathrm{L}^{-1}$, (b,e) $2.5 \mathrm{mg} \mathrm{L}^{-1}$, and (c,f) $5 \mathrm{mg} \mathrm{L}^{-1}$.

Figure S10.Correlation between log removal and contribution of (a) $\mathrm{HO}^{\bullet}$ and (b) RCS for degradation of ATN, CAF, DEET, TCE, and 1,4-D for all conditions tested in this study; (c) comparing contribution of $\mathrm{HO}^{\circ}$ and RCS for the removal of ATN, CAF, DEET, TCE, and 1,4-D from $\mathrm{RO}$ permeate by $\mathrm{UV}-\mathrm{NH}_{2} \mathrm{Cl}$ AOP in the presence of $0,2.5$, and $5 \mathrm{mg} \mathrm{L}^{-1}$.

Figure S11. Plot showing log removal of 1,4-D with increase in $\mathrm{NH}_{2} \mathrm{Cl}$, for three different fluence conditions, in absence of $\mathrm{H}_{2} \mathrm{O}_{2}$ 
Figure S12. Trends showing the effect of fluence on the log removal of trace contaminants in presence

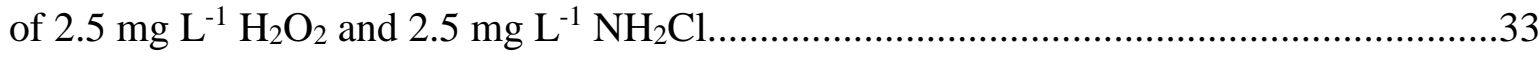

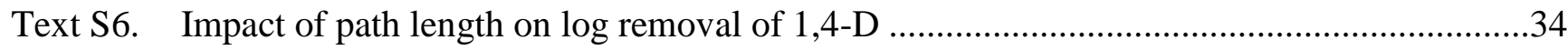

Figure S13. The effect of increasing pathlength of single-lamp axial flow reactor (UV-AOP pilot reactor) on log removal of 1,4-D from RO permeate under various photo-oxidant conditions and decreasing percent transmittance ( $\mathrm{UVT}_{254}, \% \mathrm{~T}$ ), (a) $99.9999 \% \mathrm{~T}$, (b) $99 \% \mathrm{~T}$, (c) $95 \% \mathrm{~T}$, and (d) $90 \% \mathrm{~T}$.

Figure S14. (a) Scatter plot showing log removal and fraction of $\mathrm{HO}^{\circ}$ scavenged by $\mathrm{NH}_{2} \mathrm{Cl}$ and $\mathrm{H}_{2} \mathrm{O}_{2}$, with increase in molar ratio of $\mathrm{H}_{2} \mathrm{O}_{2}$ to $\mathrm{NH}_{2} \mathrm{Cl}$. (b) Surface plot showing the effect of $\mathrm{H}_{2} \mathrm{O}_{2}$ (0 to $6.5 \mathrm{mg} \mathrm{L}^{-1}$ ) and $\mathrm{NH}_{2} \mathrm{Cl}\left(0\right.$ to $\left.9.5 \mathrm{mg} \mathrm{L}^{-1}\right)$ in pilot-scale feed water on the log removal of $1,4-\mathrm{D} \ldots$

Figure S15. Heat maps showing log removal prediction of trace contaminants (left) contaminants for which $\mathrm{Cl}^{\circ}$ is the primary RCS; (right) contaminants for which $\mathrm{Cl}_{2}{ }^{-}$is the primary RCS. . .38

Figure $\mathrm{S} 16$. Effect of $\mathrm{NH}_{2} \mathrm{Cl}$ on the concentration of $\mathrm{H}_{2} \mathrm{O}_{2}$ in $\mathrm{RO}$ permeate measured by the titanium

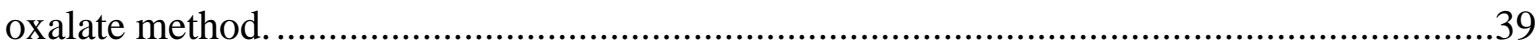

Figure S17. Effect of $\mathrm{H}_{2} \mathrm{O}_{2}$ on $\mathrm{NH}_{2} \mathrm{Cl}$ concentration (as determined by DPD method).

Text S7. Determination of second-order rate constants for reaction of atenolol and reactive chlorine species.

REFERENCES 
Text S1. Competition kinetics method for the quantification of radical steady-state concentrations Determination of steady-state concentrations in pilot-scale reactor

The steady-state concentrations of radicals in the UV-advanced oxidation process (AOP) pilot-scale reactor were calculated using a competition kinetic method using nitrobenzene (NB), a probe for hydroxyl radical $\left(\mathrm{HO}^{\circ}\right)$; benzoic acid (BA), a probe for amino- (or amidogen) radical ( $\left.{ }^{\circ} \mathrm{NH}_{2}\right), \mathrm{HO}^{\bullet}$, and all reactive chlorine species (RCS); and, fumaric acid (FA), a probe for chlorine atom $\left(\mathrm{Cl}^{\circ}\right)$ and $\mathrm{HO}^{\circ}$. In general, the rate of degradation of any compound in a UV-AOP system may be expressed as in the form of the differential equation shown in Eq S1.

$\frac{d[C]}{d t}=-k_{d}^{\prime}-\sum\left(k_{C, R}^{\prime \prime} \cdot[C] \int_{0}^{t}\left[R^{\bullet}\right]\right)$

where, $k_{d}^{\prime}$ is the first-order rate constant for direct photolysis, $k_{C, R}^{\prime \prime}$ is second-order rate constant between the compound $C$ and the radical $\left[R^{\bullet}\right]$. Assuming steady-state concentrations of $R^{\bullet}$, the degradation of compound $C$ can be expressed by the equation shown in Eq S2.

$\ln \left(\frac{C}{c_{o}}\right)=-k^{\prime}{ }_{o b s} t=-k_{d}^{\prime} t-\sum\left(k^{\prime \prime}{ }_{C, R} \cdot\left[R^{\bullet}\right]_{S S}\right) t$

where, $C_{o}$ is the initial concentration, $k^{\prime}{ }_{o b s}$ is the observed pseudo first-order rate constant, and $\left[R^{\bullet}\right]_{s s}$ is the steady-state concentration of $R^{\bullet}$. For the UV-AOP pilot reactor, a residence time of $t=25 \mathrm{~s}$ resulted in effective fluence of $850 \pm 50 \mathrm{~mJ} \mathrm{~cm}^{-2}$ (see Text S3). The reaction of $\mathrm{NB}$ with $\mathrm{HO}^{\bullet}\left(k^{\prime \prime}{ }_{N B, H O}=4.7 \times\right.$ $\left.10^{9} \mathrm{M}^{-1} \mathrm{~s}^{-1}\right)^{1}$ proceeds through the reaction:

$\mathrm{NB}+\mathrm{HO}^{\bullet} \rightarrow$ products

Reaction S1

Both, FA and BA, have high reactivity with reactive chlorine species in addition to $\mathrm{HO}^{\bullet}\left(k_{F A, H O \bullet}^{\prime \prime}=4.7\right.$ $\left.\times 10^{9} \mathrm{M}^{-1} \mathrm{~s}^{-1}, k_{B A, H O}^{\prime \prime}=6.0 \times 10^{9} \mathrm{M}^{-1} \mathrm{~s}^{-1}\right)^{2,3}$.

$B A+H O^{\bullet} \rightarrow$ products

Reaction S2

$F A+H O^{\bullet} \rightarrow$ products

Reaction S3 
For FA, $\mathrm{Cl}{ }^{\bullet}$ is the major $\operatorname{sink}\left(k^{\prime \prime}{ }_{F A, C l \bullet}=3.0 \times 10^{9} \mathrm{M}^{-1} \mathrm{~s}^{-1}\right) \cdot{ }^{4} \mathrm{BA}$ is known to be reactive with $\mathrm{Cl}^{\cdot}$ as well as a range of other radicals. Hence, FA was used to determine $\left[\mathrm{Cl}^{*}\right]_{s S}$, and BA was used to estimate the general reactivity of other reactive species generated by reverse osmosis (RO) permeate in the mixedoxidant system (Figure S1).

$\mathrm{FA}+\mathrm{Cl}^{\bullet} \rightarrow$ products

Reaction S4

$\mathrm{BA}+\mathrm{Cl} l^{\bullet}$ products Reaction S5

Note that all probe compounds undergo negligible direct photolysis in the UV reactor. Hence, $\left[\mathrm{HO}^{\bullet}\right]_{s s}$ and $\left[\mathrm{Cl}^{*}\right]_{s s}$ were calculated by determining loss of NB, BA, and FA in the UV-AOP reactor to solve the system of equations using Eq S3-S6

$\ln \left(\frac{N B}{N B_{O}}\right)=-k^{\prime \prime}{ }_{N B, H O} \cdot\left[H O^{\bullet}\right]_{s s} t$

$\ln \left(\frac{F A}{F A_{o}}\right)=-k_{F A, H O}^{\prime \prime}\left[H O^{\bullet}\right]_{S S} t-k^{\prime \prime}{ }_{F A, C l}\left[C l^{\bullet}\right]_{S S} t$

$\ln \left(\frac{B A_{o}}{B A}\right)=-k^{\prime \prime}{ }_{B A, H O} \cdot\left[H O^{\bullet}\right]_{S S} t-k^{\prime \prime}{ }_{B A, C l \cdot}\left[C l^{\bullet}\right]_{S S} t-k_{B A, \text { other }}^{\prime} t$

\section{Extending steady-state concentration of radicals in pilot-scale for indicator compounds}

In the UV-AOP pilot reactor, monochloramine $\left(\mathrm{NH}_{2} \mathrm{Cl}\right)$ and hydrogen peroxide $\left(\mathrm{H}_{2} \mathrm{O}_{2}\right)$ absorb UV light (at $254 \mathrm{~nm}$ ) and undergo photolysis to form $\mathrm{HO},{ }^{\circ} \mathrm{NH}_{2}$, and $\mathrm{Cl}^{\circ}$ in $\mathrm{UV}-\mathrm{H}_{2} \mathrm{O}_{2}-\mathrm{NH}_{2} \mathrm{Cl}$ system. The concentration of dichloramine $\left(\mathrm{NHCl}_{2}\right)$ in $\mathrm{RO}$ permeate was at the most $30 \%$ of $\mathrm{NH}_{2} \mathrm{Cl}$. Due to lower molar absorbance of $\mathrm{NHCl}_{2}$ compared to $\mathrm{NH}_{2} \mathrm{Cl}, \mathrm{NHCl}_{2}$ was not significant under most of the photooxidant conditions in this study. In $\mathrm{RO}$ permeate, chloride reacts with $\mathrm{Cl}^{*}$ to form $\mathrm{Cl}_{2}{ }^{\circ}$ that subsequently forms $\mathrm{HClO}^{*}$ that reacts with water to generate $\mathrm{HO}^{*}$. Formation of $\mathrm{Cl}^{\circ}$ from $\mathrm{HClO}^{\circ}$ is not relevant to this system as it only takes place at low $\mathrm{pH} .{ }^{5}$ Thus, the rate of formation of $\mathrm{Cl}^{\bullet}\left(r_{\text {form, } C l \bullet}\right)$ is dependent on the rate of $\mathrm{NH}_{2} \mathrm{Cl}$ photolysis. 


$$
\begin{aligned}
r_{\text {form }, \mathrm{Cl} \bullet}= & -\phi_{C l \bullet, \mathrm{NH} 2 \mathrm{Cl}} \frac{d\left[\mathrm{NH}_{2} \mathrm{Cl}\right]}{d t} \\
& =\phi_{C l \bullet, \mathrm{NH} 2 \mathrm{Cl}}\left(2.303 \times \varepsilon_{254, \mathrm{NH} 2 \mathrm{Cl}} \phi_{254, \mathrm{NH} 2 \mathrm{Cl}} \times I_{O} \times\left[\mathrm{NH}_{2} \mathrm{Cl}\right]\right)
\end{aligned}
$$

where $\phi_{C l \bullet, N H 2 C l}$ represents the moles of $\mathrm{Cl}^{\bullet}$ formed per mole of $\mathrm{NH}_{2} \mathrm{Cl}$ photolyzed, $\varepsilon_{254, N H 2 C l}$ is the molar absorption coefficient of $\mathrm{NH}_{2} \mathrm{Cl}$ at $254 \mathrm{~nm}, \phi_{254, \mathrm{NH} 2 \mathrm{Cl}}$ is the quantum yield of $\mathrm{NH}_{2} \mathrm{Cl}$ (i.e., moles of $\mathrm{NH}_{2} \mathrm{Cl}$ photolysis per mole of photons absorbed), $I_{o}$ is the incident photon flux of light. Similarly, the rate of $\mathrm{HO}^{*}$ formation $\left.\left(r_{\text {form }, \mathrm{HO}} \cdot\right)\right)$ is a function of photolysis of $\mathrm{H}_{2} \mathrm{O}_{2}$ and $\mathrm{NH}_{2} \mathrm{Cl}$.

$$
\begin{aligned}
r_{\text {form }, \mathrm{HO} \bullet}= & -\phi_{\mathrm{HO} \cdot \mathrm{H} 2 \mathrm{OO} 2} \frac{d\left[\mathrm{H}_{2} \mathrm{O}_{2}\right]}{d t}-f \phi_{\mathrm{Cl}, \mathrm{NH} 2 \mathrm{Cl}} \frac{d\left[\mathrm{NH}_{2} \mathrm{Cl}\right]}{d t} \\
= & \phi_{\mathrm{HO} \cdot \mathrm{H} 2 \mathrm{O} 2}\left(2.303 \times \varepsilon_{254, \mathrm{H} 2 \mathrm{O} 2} \phi_{254, \mathrm{H} 2 \mathrm{OO} 2} \times I_{O} \times\left[\mathrm{H}_{2} \mathrm{O}_{2}\right]\right)+f \times \phi_{C l \bullet, N H 2 C l}(2.303 \times \\
& \left.\varepsilon_{254, \mathrm{NH} 2 \mathrm{Cl}} \phi_{254, \mathrm{NH} 2 \mathrm{Cl}} \times I_{O} \times\left[\mathrm{NH}_{2} \mathrm{Cl}\right]\right)
\end{aligned}
$$

where $\phi_{\mathrm{HO} \cdot \mathrm{H} 2 \mathrm{O} 2}$ represents the moles of $\mathrm{HO}^{\bullet}$ formed per mole of $\mathrm{H}_{2} \mathrm{O}_{2}$ photolyzed, $f$ is the fraction of $\mathrm{Cl}^{*}$ that can react with $\mathrm{Cl}^{-}$to subsequently forms $\mathrm{HO}^{*}$. Note that the presence of probes and indicator compounds does not significantly impact the value of $f$, as the observed first-order rate constants for reaction of model compounds with $\mathrm{Cl}^{\circ}$ are lower than that of the reaction of $\mathrm{Cl}^{\circ}$ and $\mathrm{Cl}^{-}$. For $\mathrm{HO}^{\circ}$, the potential sinks are reaction with photo-oxidants, and the RO permeate matrix (primarily consisting of alkalinity, and total organic carbon), in addition to reaction with probe and model compounds, and other reactive intermediates. The general steady-state concentrations for this system is expressed by Eq S8.

$$
\begin{aligned}
& \frac{d\left[\mathrm{HO}^{\bullet}\right]}{d t}=0=r_{f o r m, H O}-k^{\prime \prime}{ }_{\mathrm{H} 2 \mathrm{O} 2, \mathrm{HO}} \cdot\left[\mathrm{H}_{2} \mathrm{O}_{2}\right]\left[\mathrm{HO}^{\bullet}\right]_{s S}-k^{\prime \prime}{ }_{\mathrm{NH} 2 \mathrm{Cl}, \mathrm{HO}} \cdot\left[\mathrm{NH}_{2} \mathrm{Cl}\right]\left[\mathrm{HO}^{\bullet}\right]_{S S}- \\
& k^{\prime \prime}{ }_{N B, H O} \cdot[N B]\left[H O^{\bullet}\right]_{S S}-k_{F A, H O}^{\prime \prime}[F A]\left[H O^{\bullet}\right]_{S S}-k_{B A, H O}^{\prime \prime}[B A]\left[H O^{\bullet}\right]_{S S}- \\
& k^{\prime \prime}{ }_{\mathrm{CO} 3-2, \mathrm{HO}}\left[\mathrm{CO}_{3}^{2-}\right]\left[\mathrm{HO}^{\bullet}\right]_{S S} k^{\prime \prime}{ }_{\mathrm{TOC}, \mathrm{HO}}[\mathrm{TOC}]\left[\mathrm{HO}^{\bullet}\right]_{s S}- \\
& \sum k^{\prime \prime}{ }_{\text {intermediate }, \mathrm{HO}} \cdot[\text { intermediate }]\left[\mathrm{HO}^{\bullet}\right]_{s s}
\end{aligned}
$$


In the UV-AOP reactor, the concentration of TOC, alkalinity, and reaction intermediates are low (see Text S5). Hence, Eq S8 can be further simplified and rearranged to obtain an expression for $\left[\mathrm{HO}^{\bullet}\right]_{S S}$ during the probe experiments in Eq S9.

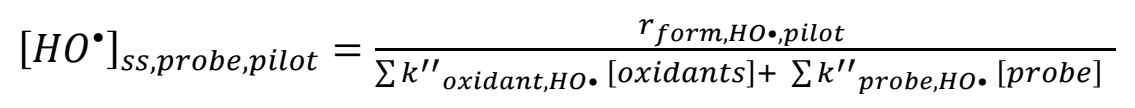

Similarly, an expression for $\left[\mathrm{HO}^{\bullet}\right]_{S S}$ can be obtained for the experimental condition for the indicator compounds in the UV-AOP reactor (Eq S10a) and bench-scale system (Eq S10b).

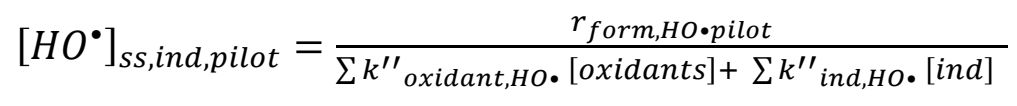

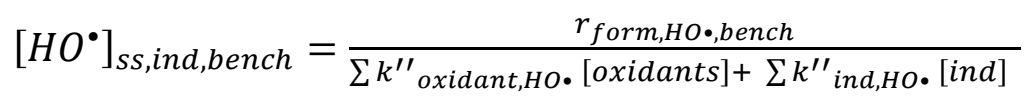

For the same concentration of $\mathrm{H}_{2} \mathrm{O}_{2}$ and $\mathrm{NH}_{2} \mathrm{Cl}$ in the $\mathrm{UV}-\mathrm{AOP}$ reactor for probe and model experiments, Eq S9 and S10a yield Eq 10c.

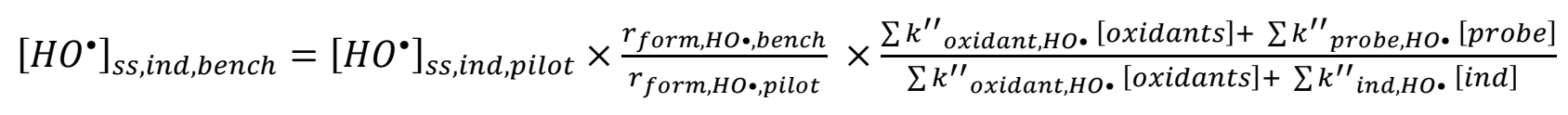

Eq S10c

For the same concentration of $\mathrm{H}_{2} \mathrm{O}_{2}$ and $\mathrm{NH}_{2} \mathrm{Cl}$ in the UV-AOP reactor for probes and model compounds in bench-scale experiments, Eq S9, S10b, and S10c yield Eq 10d.

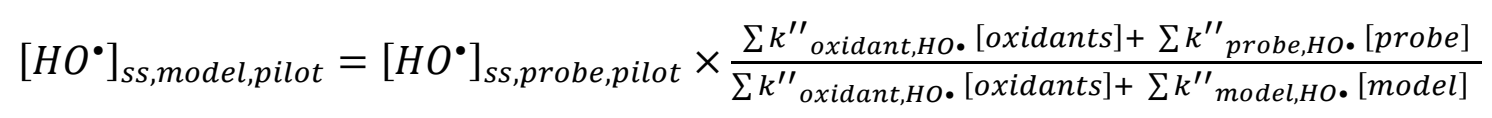

Note that for most of these experiments [oxidants] > [probes] [ind].

\section{Calculating contribution of HO• and RCS in degradation indicator compounds}

The generic equation, Eq S2, may be expanded to obtain an equation to describe degradation of a trace organic contaminant $(\mathrm{C})$ in the UV-AOP reactor.

$\ln \left(\frac{C}{C_{o}}\right)=-k^{\prime}{ }_{o b s} t$ 


$$
=-k^{\prime}{ }_{d} t-k^{\prime \prime}{ }_{C, H O} \cdot\left[H O^{\bullet}\right]_{s S} t-\sum k^{\prime \prime}{ }_{C, R C S i}\left[R C S_{i}\right]_{s s} t
$$

Eq S11a

where, $k_{C, H O}^{\prime \prime}$ and $k_{C, R C S i}$ are the second order rate constants for degradation of $\mathrm{C}$ with $\mathrm{HO} \bullet$ and relevant RCS, whose steady-state concentrations is depicted by $\left[R C S_{i}\right]_{s s}$. Thus, the relative contribution of $\mathrm{HO}^{\bullet}$ and direct photolysis toward indicator contaminant degradation is obtained by Eq $11 \mathrm{~b}, \mathrm{c}$.

contribution of direct photolysis $=\frac{k^{\prime}{ }_{d}}{k^{\prime}{ }_{o b s}}$

Eq S11b

contribution of $\mathrm{HO}^{\bullet}=\frac{k^{\prime \prime}{ }_{C, H O} \cdot\left[\mathrm{HO}^{\circ}\right]_{s S}}{k^{\prime}{ }_{\text {obs }}}$

Eq S11c

Note that $k^{\prime}{ }_{d}, k^{\prime \prime}{ }_{C, H O},\left[\mathrm{HO}^{\bullet}\right]_{S S}$ were determined independently in this study. The contribution of RCS is then determined by Eq 11d

contribution of $R C S=1-\frac{k^{\prime} d}{k^{\prime}{ }_{o b s}}-\frac{k^{\prime \prime}{ }_{C, H O}\left[\mathrm{HO}^{\circ}\right]_{S S}}{k^{\prime}{ }_{\text {obs }}}$

\section{Predicting log removals of for hypothetical compounds of known reactivity.}

Eq S11a may also be used to make theoretical prediction of the log removal of indicator compound in full-scale systems for which the reactivity $\left(k^{\prime \prime}\right)$ with relevant reactive species, $R$, is already known.

$$
\begin{aligned}
& \text { Predicted log removal }=\log _{10}\left(\frac{C_{o}}{C}\right)=\log _{10}\left(e^{k^{\prime}} \text { obs } t\right) \\
& =\log _{10}\left(e^{\left(k^{\prime \prime}{ }_{C, H O} \cdot\left[H O^{*}\right]_{s S} t+k^{\prime \prime}{ }_{C, R C S i}\left[R C S_{i}\right]_{s S} t\right)}\right)
\end{aligned}
$$

In this study, the degradation of indicator compounds was assumed to be driven $\mathrm{HO}^{\bullet}$ and $\mathrm{Cl}^{\bullet}$ or $\mathrm{HO}^{\bullet}$ and $\mathrm{Cl}_{2}{ }^{\bullet}\left(\right.$ see Text S5). Based on discussion of probe-based analysis above, $\left[R^{\bullet}\right]_{S S}$ may be determined using probes and these values may be extended to the analysis of trace contaminant removal. Thus, values of $\left[\mathrm{HO}^{*}\right]_{\mathrm{ss}}$ and $\left[\mathrm{Cl}^{*}\right]_{\mathrm{ss}}$ for various conditions in pilot-scale reactor (and by extension, full-scale system) are obtained from probe-based methods. A theoretical estimate of $\left[\mathrm{Cl}_{2}{ }^{\circ}\right]_{\mathrm{ss}}$ was made by treating $1,4-\mathrm{D}$ as probe compound. Note that direct photolysis was negligible for all indicator compounds other than TCE. 

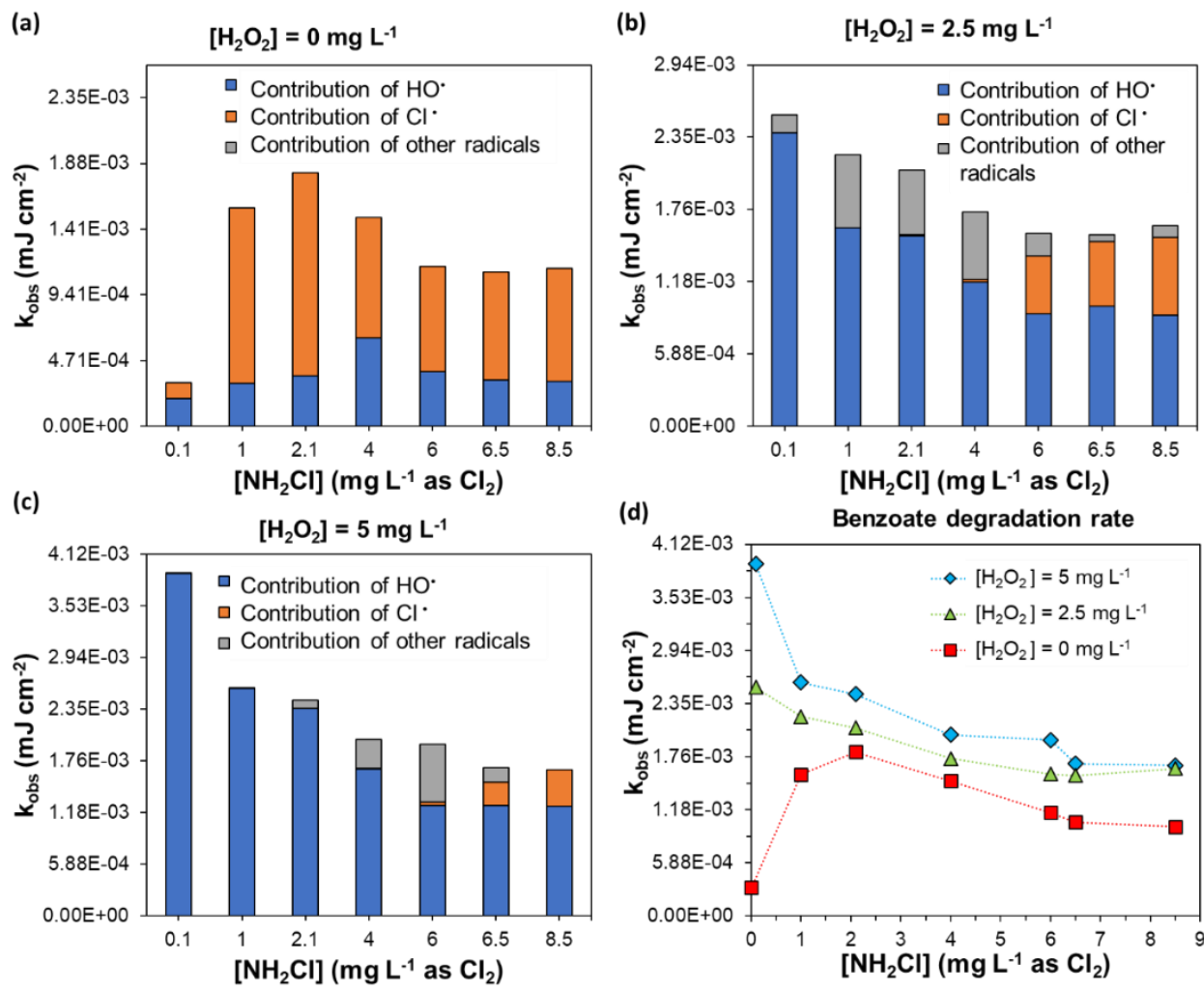

Figure S1. Degradation of benzoate in pilot reactor showing the contribution of $\mathrm{HO}^{\circ}, \mathrm{Cl}^{\circ}$, and other radical species in degradation at different doses of $\mathrm{H}_{2} \mathrm{O}_{2}$. Previous studies ${ }^{6,7}$ have reported that relevance of $\mathrm{Cl}_{2}{ }^{--}$in chloramine impacted $\mathrm{UV}-\mathrm{H}_{2} \mathrm{O}_{2}$ systems, which can react with $\mathrm{BA}^{7}$. $\mathrm{ClO}^{\bullet}$ and $\mathrm{ClHO}^{*}$ are not expected to form in this system, due to low concentrations of hypochlorite $(\mathrm{HOCl}<0.05$ $\left.\mathrm{mg} \mathrm{L}^{-1}\right)$. Similarly, formation of other reactive chlorine species (RCS) in RO permeate was not expected in UV-based systems ${ }^{8}$. Furthermore, BA reacts with the ${ }^{\circ} \mathrm{NH}_{2}{ }^{5}$; however, this rate constant is low for other organic compounds ${ }^{5}$. Note that the concentration of other precursor molecules in RO permeate is relatively low ([bicarbonate] $<8 \mathrm{mg} \mathrm{L}^{-1}$ as $\mathrm{CaCO}_{3} ;\left[\mathrm{Br}^{-}\right]<0.3 \mathrm{mg} \mathrm{L}^{-1}$ ), and were are not expected to form reactive species at appreciable concentrations in $\mathrm{UV}-\mathrm{AOP}$ system. Thus $\mathrm{HO}^{\circ}, \mathrm{Cl}^{\circ}$, and $\mathrm{Cl}_{2}{ }^{\circ-}$ were the relevant reactive species for trace contaminant degradation in the chloramine-impacted UV- $\mathrm{H}_{2} \mathrm{O}_{2}$ system. Experimental conditions: RO permeate; $\mathrm{pH} 5.8$; fluence $=850 \mathrm{~mJ} \mathrm{~cm}^{-2}$; $[\mathrm{NB}]=100 \mu \mathrm{g} \mathrm{L}^{-1}(825$ $\mathrm{nM}) ;[\mathrm{BA}]=100 \mu \mathrm{g} \mathrm{L}^{-1}(820 \mathrm{nM}) ;[\mathrm{FA}]=100 \mu \mathrm{g} \mathrm{L}^{-1}(830 \mathrm{nM})$. 


\section{Text S2. Details on analytical methods}

Concentrations of chloramines were quantified using the standard DPD method and expressed as mg L ${ }^{-1}$ as $\mathrm{Cl}_{2}{ }^{11}$ Note that the stock solution of $\mathrm{NH}_{2} \mathrm{Cl}$ prepared contained less than $5 \% \mathrm{NHCl}_{2}$. The $\mathrm{NH}_{2} \mathrm{Cl}$ stock was discarded if $\mathrm{NHCl}_{2}$ concentration was found to be greater than $5 \%$. Thus, in both our pilot-scale and bench-scale experiments, we added only $\mathrm{NH}_{2} \mathrm{Cl}$ without introducing $\mathrm{NHCl}_{2}$ in the system. Hence, the concentration of $\mathrm{NHCl}_{2}$ was, at most $30 \%$, corresponding to the case when no additional $\mathrm{NH}_{2} \mathrm{Cl}$ was added to $\mathrm{RO}$ permeate $\left(\left[\mathrm{NH}_{2} \mathrm{Cl}\right]=2.5 \mathrm{mg} / \mathrm{L}\right)$. In all other oxidant conditions tested, $\mathrm{NHCl}_{2}$ was between 1 to $8 \%$ of chloramine concentration. $\mathrm{H}_{2} \mathrm{O}_{2}$ was measured using the titanium oxalate method. ${ }^{12}$ The presence of chloramines (up $10 \mathrm{mg} \mathrm{L}^{-1}$ ) in the RO permeate did not interfere with the titanium oxalate $\mathrm{H}_{2} \mathrm{O}_{2}$ analysis; similarly, the presence of $\mathrm{H}_{2} \mathrm{O}_{2}$ did not impact the chloramine measurement by the DPD standard method (Figures S16-S17). ACT samples were derivatized using 2,4-dinitrophenylhydrazone (DNPH) followed by HPLC-DAD analysis. ${ }^{13}, 14$ Details of the chromatographic elution for other compounds is provided below.

\section{Probe compounds (benzoic acid, fumaric acid, nitrobenzene)}

Aqueous solutions of benzoic acid (BA), fumaric acid (FA), and nitrobenzene (NB) were detected on high performance liquid chromatography (HPLC, Agilent 1200 Series) system equipped with diode array detector (DAD) within six hours of experiments. Samples were placed in 2 mL vials with minimal headspace. Prior to analysis. the $\mathrm{pH}$ of sample was adjusted to $\sim 2.8$ using $50 \mu \mathrm{L}$ of $2 \%$ formic acid. Deionized water (DI, 95\%) and acetonitrile (5\%), each buffered with $0.04 \%$ formic acid, were used as eluents at a flow rate of $1 \mathrm{~mL} \mathrm{~min}^{-1}$ on an Agilent Eclipse XDB-C18 column using the following gradient method: ramped up at $+22.5 \%$ acetonitrile per min at $2.5 \mathrm{~min}$, held constant for $3 \mathrm{~min}$, and ramped down at $-22.5 \%$ acetonitrile per min at $7.5 \mathrm{~min}$. Post elution equilibration was 
performed at 5\% acetonitrile for $3.5 \mathrm{~min}$. The retention time was $6.2 \mathrm{~min}$ for FA, $8.1 \mathrm{~min}$ for BA, and $10.9 \min$ for NB.

\section{Indicator compounds (ATN, CAF, DEET)}

Samples containing indicator compounds ATN, CAF, and DEET were acidified using formic acid, and stored in $2 \mathrm{~mL}$ HPLC vials at $-20{ }^{\circ} \mathrm{C}$ until analysis by liquid chromatography coupled with electrospray ionization mass spectrometry (LC-ESI-MS, Shimadzu LC4000). A Kinetex@ C-18 column $\left(50 \mathrm{~mm} \times 2.1 \mathrm{~mm} \times 2.6 \mu \mathrm{m}\right.$.) was used for separation at a flow rate of $0.5 \mathrm{~mL} \mathrm{~min}^{-1}$ at $30^{\circ} \mathrm{C}$, using LCMS-grade acetonitrile and LCMS-grade water, each buffered with $0.1 \%$ formic acid. The column was equilibrated using $5 \%$ acetonitrile and $95 \%$ water for $2 \mathrm{~min}$. Then, the acetonitrile was increased to reach $50 \%$ by $6 \mathrm{~min}$. This gradient was held for $1 \mathrm{~min}$, after which, the acetonitrile was reduced to $5 \%$ at 8 min. Post elution balancing occurred for 2 min with $5 \%$ acetonitrile. The retention time of ATN, CAF, and DEET were 1.51, 3.22, and 5 min, respectively. Heated-ESI was performed at $300{ }^{\circ} \mathrm{C}$ and $4.5 \mathrm{kV}$, using nitrogen gas as nebulizing and drying gas. All compounds were detected in positive ion mode $(\mathrm{m} / \mathrm{z}=267.3$ for ATN, 132.1 for CAF, and 192.2 for DEET $)$.

\section{Indicator compounds $(1,4-D)$}

Aqueous solutions of 1,4-D were extracted and analyzed per EPA Method 522. Samples from the pilot-scale reactor were stored with no headspace at $4{ }^{\circ} \mathrm{C}$ and were extracted and analyzed within two weeks. Approximately $100 \mathrm{~mL}$ of aqueous sample containing 1,4-D was spiked with $1 \mu \mathrm{g}$ of deuterated 1,4-D (1,4-D-d8) as a surrogate standard to determine the extraction efficiency. AC-2 short SPE cartridges (Waters, Millford PA) were washed with $1 \mathrm{~mL}$ GC-MS grade dichloromethane (DCM) and $1 \mathrm{~mL}$ HPLC-grade methanol. The cartridge was conditioned with $2 \mathrm{~mL}$ methanol and $2 \mathrm{~mL}$ water; the 
sample was loaded on to the cartridge at an average rate of $8 \pm 2 \mathrm{~mL} \mathrm{~min}^{-1}$. The cartridge was now allowed to dry during conditioning and loading. The 1,4-D and 1,4-D-d8 were eluted into a calibrated graduated test tube with $1.8 \mathrm{~mL}$ DCM and were taken up to $2 \mathrm{~mL}$ with DCM. Prior to drying with anhydrous sodium carbonate, THF-d8 $(1 \mu \mathrm{g})$ was spiked into the sample for use as internal standard. Samples were stored in $2 \mathrm{~mL}$ HPLC vials with minimal headspace at $4{ }^{\circ} \mathrm{C}$ for a maximum of 5 days prior to analysis. All extractions were performed in duplicate with a $90 \pm 12 \%$ mean recovery for the extraction method. The samples were analyzed by GC-MS using a helium carrier gas. The thermal gradient described in EPA Method 522 was modified for Agilent DB-624UI column as follows: 0 to $7.5 \mathrm{~min}$ at $30{ }^{\circ} \mathrm{C} ; 7.5$ to $11.5 \mathrm{~min}$ at a thermal ramp to $250{ }^{\circ} \mathrm{C}$, which was held for $3 \mathrm{~min}$, after which temperature was held at $30{ }^{\circ} \mathrm{C}$ for $0.5 \mathrm{~min}$. Injection was performed in splitless mode, and inlet temperature was held at $200{ }^{\circ} \mathrm{C}$. Sample volume was $1 \mu \mathrm{L}$. The ionization current of ion trap was set at $10,000 \mathrm{~mA}$ at a scan rate of $0.1 \mathrm{~s}$. Retention times were $5.4 \mathrm{~min}$ for THF-d8 (m/z: 46, 78, 80), $6.6 \mathrm{~min}$ for 1,4-D-d8 (m/z: 62, 64, 96), and $6.8 \mathrm{~min}$ for 1,4-D (m/z: 58, 88).

\section{Indicator compounds (TCE)}

Experimental samples consisting of aqueous solutions of TCE were stored with no headspace. Calibrated needle syringes were used to make all liquid transfers. Liquid-liquid extraction of TCE, described by the EPA, ${ }^{15}$ was modified to use DCM for extraction. In short, $2.5 \mathrm{~mL}$ DCM was added to $20 \mathrm{~mL}$ sample containing TCE and shaken vigorously for $2 \mathrm{~min}$ on vortex shaker. The solution was allowed stand for 10 min to separate the DCM layer from water. Then, $2 \mathrm{~mL}$ of DCM was transferred to graduated test tube. After the addition internal standard (1 $\mu \mathrm{g}$ THF-d8), sample was dried with anhydrous sodium carbonate, and stored in $2 \mathrm{~mL}$ HPLC vials with minimal headspace. Samples were analyzed by GC-MS with the gradient and column described above. The retention time of TCE was 
$6.5 \mathrm{~min}$, and $\mathrm{m} / \mathrm{z}=133$ was chosen as primary mass fragment, based on abundance. Deuterated TCE was not used as internal standard due to difficulty in chromatographic separation and significant overlap in mass spectra. The recovery of TCE for each sample was determined using multiple standard addition techniques. A fortified blank sample indicated $\sim 95 \%$ recovery of TCE. Loss by volatilization loss was found to be less than $5 \%$. All samples were extracted in duplicate.

Table S1. Average water quality of reverse osmosis permeate over experimentation period. Error represents the standard deviation from nineteen data points.

\begin{tabular}{lll}
\hline & units & Average \\
\hline TOC & $\mu \mathrm{g} \mathrm{L}^{-1}$ as C & $47.1 \pm 4.5$ \\
$\mathrm{pH}$ & $\mathrm{pH}$ units & $5.8 \pm 0.1$ \\
Total chloramine & $\mathrm{Mg} \mathrm{L}^{-1}$ as $\mathrm{Cl}_{2}$ & $3.2 \pm 0.6$ \\
$\mathrm{UVT}_{254}$ & $\%$ & $97.1 \pm 1.2$ \\
Chloride & $\mathrm{mg} \mathrm{L}^{-1}$ & $0.2 \pm 0.03$ \\
Alkalinity & $\mathrm{mg} \mathrm{L}^{-1}$ as $\mathrm{CaCO}_{3}$ & $11.5 \pm 0.3$ \\
Bicarbonate & $\mathrm{Mg} \mathrm{L}^{-1}$ as $\mathrm{CaCO}_{3}$ & $7.8 \pm 0.2$ \\
Conductivity & $\mu \mathrm{S} \mathrm{cm}^{-1}$ & $33.1 \pm 9.5$ \\
\hline
\end{tabular}




\section{Text S3. Details on pilot-scale UV oxidation experiments}

Pilot-scale UV experiments were conducted on-site, at an advanced water reuse treatment facility in Southern California, which operates the largest indirect potable reuse treatment system in the United States. ${ }^{9}$ The full-scale, membrane-based facility produces 100 million gallons of recycled water per day (i.e., $3.79 \times 10^{5} \mathrm{~m}^{3} \mathrm{day}^{-1}$ ). The chemical composition of real-time RO permeate was characterized on each day of experimentation and remained consistent ( $\pm 15 \%$ variation) over the 2 -year study (Table $\mathrm{S} 1)$. The RO permeate used in pilot-scale reactor was diverted from the full-scale treatment train. Two modes were made available for experiments. First, where RO permeate from the full-scale treatment train was fed directly into the pilot-scale UV reactor. Second, RO permeate was collected in a 350-gallon breaktank (and used within 1 hour). For this study, the break tank was used to avoid fluctuations in the chloramine concentrations of RO permeate.

An axial flow-through UV reactor that housed a single 257-watt, low-pressure $(\lambda=254 \mathrm{~nm}) \mathrm{UV}$ lamp (Trojan Technologies), and two in-line mixers upstream of the reactor inlet for the addition of chemical reagents (Figure S2). The UV reactor was $148 \mathrm{~cm}$ in length, and had an outer diameter of $4.8 \mathrm{~cm}$. The lamp was placed in a quartz sleeve with a diameter of $2.4 \mathrm{~cm}$. Thus, the radial distance between the quartz sleeve and the wall of the lamp housing, which served as the nominal optical pathlength, was $3.4 \mathrm{~cm}$. The total volume of the active volume of the reactor between the lamp electrodes was $11 \mathrm{~L}$. The source water was pumped through the pilot reactor at a flow rate regulated at 6 gallons per minute (i.e., $0.38 \mathrm{~L} \mathrm{~s}^{-1}$ ), so that the UV fluence in the pilot-scale reactor matched that of the full-scale system. Control experiments using the degradation of $N$-Nitrosodimethylamine (NDMA) established the UV fluence at the full-scale system to be $850 \pm 50 \mathrm{~mJ} \mathrm{~cm}^{-2}$. The theoretical residence time at this flow rate was ca. $25 \mathrm{~s}$. Tracer tests with $255 \mathrm{mM} \mathrm{NaCl}$ solution injected at $12 \mathrm{~mL} / \mathrm{min}$ into the inline static mixer demonstrated that a plug flow condition was established in the UV reactor; the 
observed residence time ( $28 \mathrm{~s}$ ) was comparable to the theoretical residence time. The reactor was equipped with backpressure valves to adjust flow and ensure that the reactor was running full at all flow rates tested. No short circuiting was observed. Corresponding increase in fluence with decrease in flowrate was tested using $\mathrm{H}_{2} \mathrm{O}_{2}$ as an actinometer, and verified by measuring loss of 1,4-D at different fluence rates. In addition, lamp output was measured using radiometer (International Light Technologies, Peabody, MA) every 3 hours to ensure consistency in lamp performance.

For each experiment, the feedwater was analyzed for background chloramines and $\mathrm{H}_{2} \mathrm{O}_{2}$ concentrations. $\mathrm{NH}_{2} \mathrm{Cl}\left(0.02-9.5 \mathrm{mg} \mathrm{L}^{-1}\right.$ as $\left.\mathrm{Cl}_{2}\right)$ was chosen as the primary chloramine-based photooxidant in the system, since $\mathrm{NH}_{2} \mathrm{Cl}$ is the preferred anti-fouling chloramine in membrane-based systems. ${ }^{10}$ Concentrations of $\mathrm{H}_{2} \mathrm{O}_{2}$ were tested up to $6.5 \mathrm{mg} \mathrm{L}^{-1}$. For experimental conditions at which the target $\mathrm{NH}_{2} \mathrm{Cl}$ or $\mathrm{H}_{2} \mathrm{O}_{2}$ concentration was higher than the background concentration in real-time $\mathrm{RO}$ permeate, photo-oxidants were spiked into the permeate solutions prior to irradiation. For conditions at which the target $\mathrm{NH}_{2} \mathrm{Cl}$ concentration was below the background, measured quantities of sodium sulfite were added to the RO permeate to quench existing chloramines to desired levels. Small doses of sodium sulfite stoichiometrically compared to measured chloramine concentration in RO permeate were used; therefore, no residual sulfite was expected in RO permeate. For each experimental condition, $2.5 \mathrm{~L}$ of feed- and product-water from the UV reactor were collected and analyzed.

Indicator compounds included 1,4-D $\left(20 \pm 2.0 \mu \mathrm{g} \mathrm{L}^{-1}\right)$, ATN $\left(20 \pm 2.0 \mu \mathrm{g} \mathrm{L}^{-1}\right)$, ACT $(100 \pm$ $\left.8.0 \mu \mathrm{g} \mathrm{L}^{-1}\right)$, DEET $\left(20 \pm 2.0 \mu \mathrm{g} \mathrm{L}^{-1}\right)$, CAF $(100 \pm 8.0 \mu \mathrm{g} \mathrm{L}-1)$, and TCE $\left(8 \pm 1.2 \mu \mathrm{g} \mathrm{L}{ }^{-1}\right)$. ACT was selected based on internal reports from the full-scale treatment plant, which reported a single incident of ACT contamination resulting in concentrations $c a .350 \mu \mathrm{g} \mathrm{L}^{-1}$ in RO permeate. On these lines, CAF was added at high concentration to represent unexpected bypassing of molecules slightly larger than the nominal molecular weight cutoff (MWCO) of the membrane. For context, literature reported 
concentrations of other trace contaminants in typical RO permeate were to be in the range of $10 \mu \mathrm{g} \mathrm{L}^{-1}$ or lesser. Second-order rate constants between indicator compounds and radical species are obtained either from competition kinetics experiments (Text S7) or prior literature (Table S2). To quantify steady-state concentrations of reactive radicals, probe compounds including benzoic acid, fumaric acid, and nitrobenzene were utilized (Text S1). In addition to the pilot-scale setup, select experiments examining reaction kinetics were performed in a bench-scale UV carousel reactor, using real-time RO permeate from the same full-scale facility. The irradiation time in the bench-scale system was adjusted to match the UV-fluence of the full-scale system. Control experiments with $\mathrm{H}_{2} \mathrm{O}_{2}$ and 1,4-D showed no difference in performance of the two setups (Text S4, Figure S3) and confirmed that both bench- and pilot-scale experiments identically simulated the full-scale treatment. 


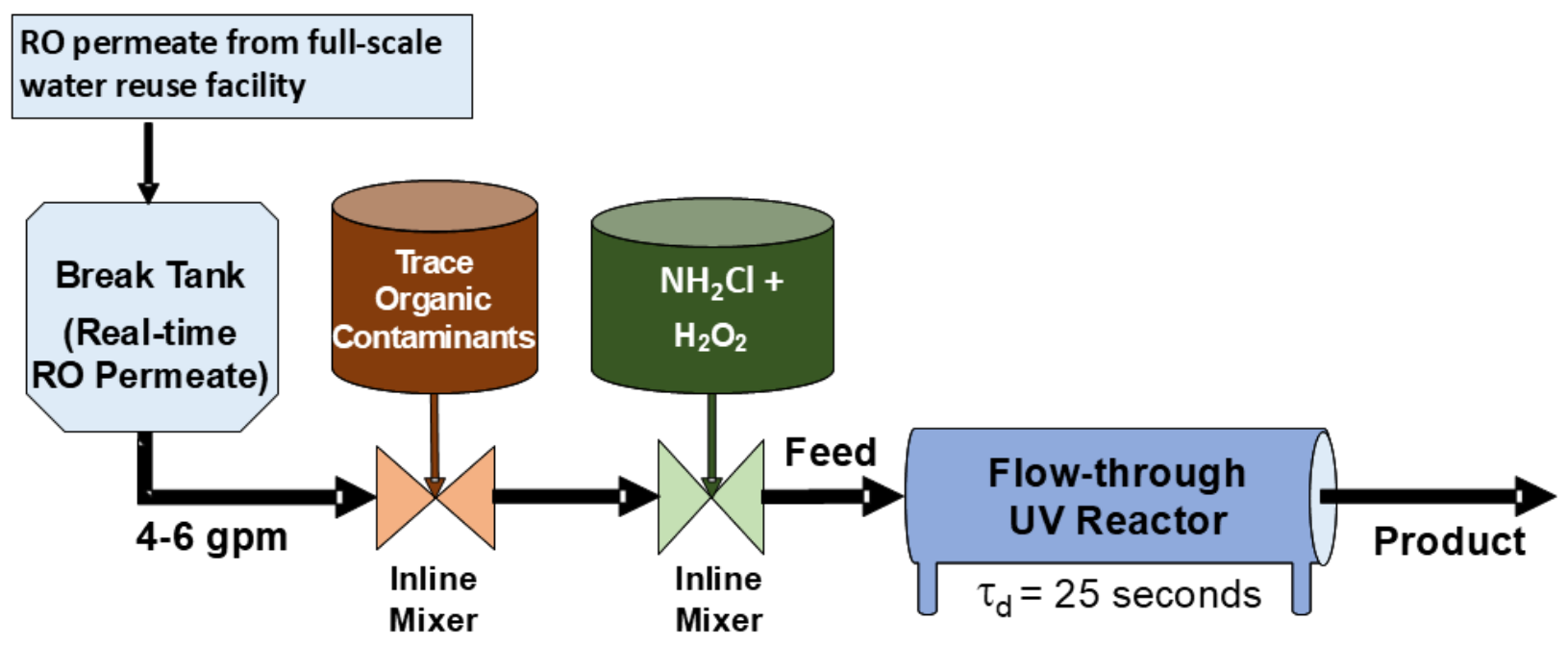

Figure S2. A schematic illustration of the pilot-scale experimental setup. Real-time RO permeate and a flow-through UV reactor were used to evaluate chloramine and hydrogen peroxide photolysis, and degradation of trace organic contaminants during UV-AOP treatment. 


\section{Text S4. Comparison of pilot-scale UV-AOP bench-scale experimental set up}

To verify performance of pilot-scale reactor, and application of batch reactor kinetics to plugflow reactor, the photodegradation experiments for select trace contaminants and probe compounds were performed in both, pilot-scale reactor and bench-scale reactor in pilot-scale conditions. Note that all experiments were conducted in real-time RO permeate, with identical oxidant additions.

For UV-AOP bench-scale experiments, a $50 \mathrm{mM} \mathrm{NH}_{2} \mathrm{Cl}$ solution was prepared via a dropwise addition of $20 \mathrm{~mL}$ of $\mathrm{NaOCl}$ solution $\left(\sim 62.5 \mathrm{mM}\right.$ as $\left.\mathrm{Cl}_{2}\right)$ to $5 \mathrm{~mL}$ of $150 \mathrm{mM}\left(\mathrm{NH}_{4}\right)_{2} \mathrm{SO}_{4}$. The solution was allowed to rest for one hour before use. All other solutions were made in a manner identical to those for pilot-scale experiments. The bench-scale reactor consisted of a carousel reactor (Ace Glass, Inc.) equipped with a low-pressure lamp ( $\lambda=254 \mathrm{~nm}$; Ultra Sun Technologies, LT001) at the center. The

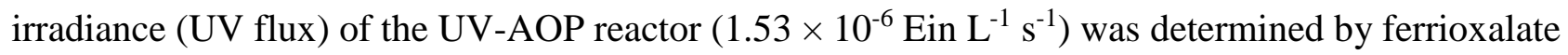

actinometry. ${ }^{16}$ Approximately $8 \mathrm{~mL}$ of test solution was placed in quartz tubes and capped with minimal headspace (effective pathlength $=0.75 \mathrm{~cm}$ ). At pre-set time points, sacrificial tubes of irradiated solutions were withdrawn from the reactor for analysis. Irradiated sample solutions were quenched with $100 \mathrm{mM}$ sodium thiosulfate and stored, with minimal headspace, at $4{ }^{\circ} \mathrm{C}$ prior to analysis. The irradiation time in the bench-scale system was adjusted to match the UV-fluence of the full-scale system $\left(850 \pm 50 \mathrm{~mJ} \mathrm{~cm}^{-2}\right)$.

Figure S3 compares the degradation of 1,4-D in OCWD pilot scale and bench-scale reactor for two conditions. The lack of significant difference in the log removal of 1,4-D in the two set ups confirm that the bench-scale experiments operated under pilot-scale conditions could predict full-scale treatment efficiency. The use of bench-scale reactor is indicated in figure captions as needed. 


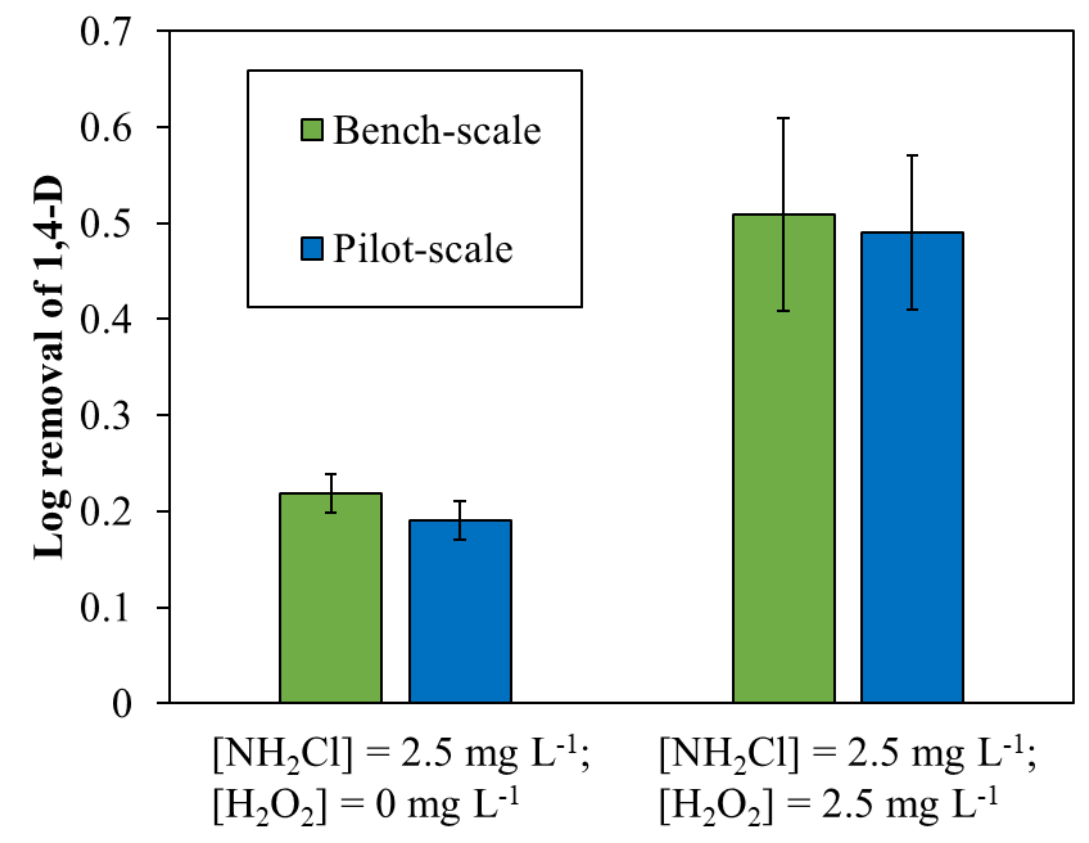

Figure S3. Bar chart showing the log removal of 1,4-D in OCWD pilot-scale reactor, described in Text S3, and bench-scale reactor. Experimental conditions: $\left[\mathrm{H}_{2} \mathrm{O}_{2}\right]=0,2.5 \mathrm{mg} \mathrm{L}^{-1} ;\left[\mathrm{NH}_{2} \mathrm{Cl}\right]=2.5 \mathrm{mg} \mathrm{L}^{-1}$; $[1,4-\mathrm{D}]=20 \mu \mathrm{g} \mathrm{L}{ }^{-1}$. Error bars are 95\% confidence interval from duplicate experiments. 
Table S2. Second-order rate constants for the reaction of relevant radicals with trace organic compounds in this study.

\begin{tabular}{|c|c|c|c|}
\hline Indicator Compound & Oxidant radical & $k\left(\mathbf{M}^{-1} \mathbf{S}^{-1}\right)$ & Reference \\
\hline 1,4-Dioxane (1,4-D) & $\mathrm{HO}^{\circ}$ & $3.10 \times 10^{9}$ & 17 \\
\hline 1,4-Dioxane (1,4-D) & $\mathrm{Cl}^{\bullet}$ & $4.38 \times 10^{6}$ & 5 \\
\hline 1,4-Dioxane (1,4-D) & $\mathrm{Cl}_{2}{ }^{\cdot-}$ & $3.30 \times 10^{6}$ & 5 \\
\hline Acetone (ACT) & $\mathrm{HO}^{\bullet}$ & $1.30 \times 10^{8}$ & 18 \\
\hline Acetone (ACT) & $\mathrm{Cl}_{2}^{\cdot-}$ & $1.40 \times 10^{3}$ & 19 \\
\hline Atenolol (ATN) & $\mathrm{HO}^{\bullet}$ & $8.00 \times 10^{9}$ & 20 \\
\hline Atenolol (ATN) & $\mathrm{Cl}^{\bullet}$ & $1.12 \times 10^{10}$ & $\begin{array}{l}\text { This study (see } \\
\text { Text S7) }\end{array}$ \\
\hline Atenolol (ATN) & $\mathrm{Cl}_{2}{ }^{\cdot-}$ & $9.81 \times 10^{6}$ & $\begin{array}{l}\text { This study (see } \\
\text { Text S7) }\end{array}$ \\
\hline Caffeine (CAF) & $\mathrm{HO}^{\bullet}$ & $6.40 \times 10^{9}$ & 21 \\
\hline Caffeine (CAF) & $\mathrm{Cl}^{\bullet}$ & $5.00 \times 10^{9 *}$ & 21 \\
\hline $\begin{array}{l}\text { N, N-Diethyl-meta-toluamide } \\
\text { (DEET) }\end{array}$ & $\mathrm{HO}^{\circ}$ & $4.95 \times 10^{9}$ & 22 \\
\hline $\begin{array}{l}\text { N, N-Diethyl-meta-toluamide } \\
\text { (DEET) }\end{array}$ & $\mathrm{Cl}^{\circ}$ & $3.80 \times 10^{9}$ & 21 \\
\hline Trichloroethylene (TCE) & $\mathrm{HO}^{\bullet}$ & $2.90 \times 10^{9}$ & 23 \\
\hline Trichloroethylene (TCE) & $\mathrm{Cl}_{2}{ }^{\cdot-}$ & $1.00 \times 10^{7}$ & 24,25 \\
\hline Trichloroethylene (TCE) & $\mathrm{Cl}^{\circ}$ & $1.98 \times 10^{8}$ & 24,25 \\
\hline
\end{tabular}

\begin{tabular}{cccc}
\hline Probe Compounds & Oxidant radical & $\boldsymbol{k}\left(\mathbf{M}^{-\mathbf{1}} \mathbf{s}^{-\mathbf{1}}\right)$ & Reference \\
\hline Benzoic acid (BA) & $\mathrm{HO}^{\circ}$ & $6.0 \times 10^{9}$ & 2 \\
Benzoic acid (BA) & $\mathrm{Cl}^{\circ}$ & $1.8 \times 10^{10}$ & 5 \\
Fumaric acid (FA) & $\mathrm{HO}^{\circ}$ & $4.7 \times 10^{9}$ & 3 \\
Fumaric acid (FA) & $\mathrm{Cl}^{\circ}$ & $3.0 \times 10^{9}$ & 4 \\
Nitrobenzene (NB) & $\mathrm{HO}^{\circ}$ & $4.7 \times 10^{9}$ & 1
\end{tabular}

*Authors provide a range of $3 \times 10^{9}-50 \times 10^{9} \mathrm{M}^{-1} \mathrm{~s}^{-1}$ for the second order rate constant for the reaction of $\mathrm{CAF}$ with $\mathrm{Cl}^{\circ}$. Furthermore, the authors indicated that $\mathrm{Cl}_{2}{ }^{\circ}$ may also contribute to $\mathrm{CAF}$ degradation. 

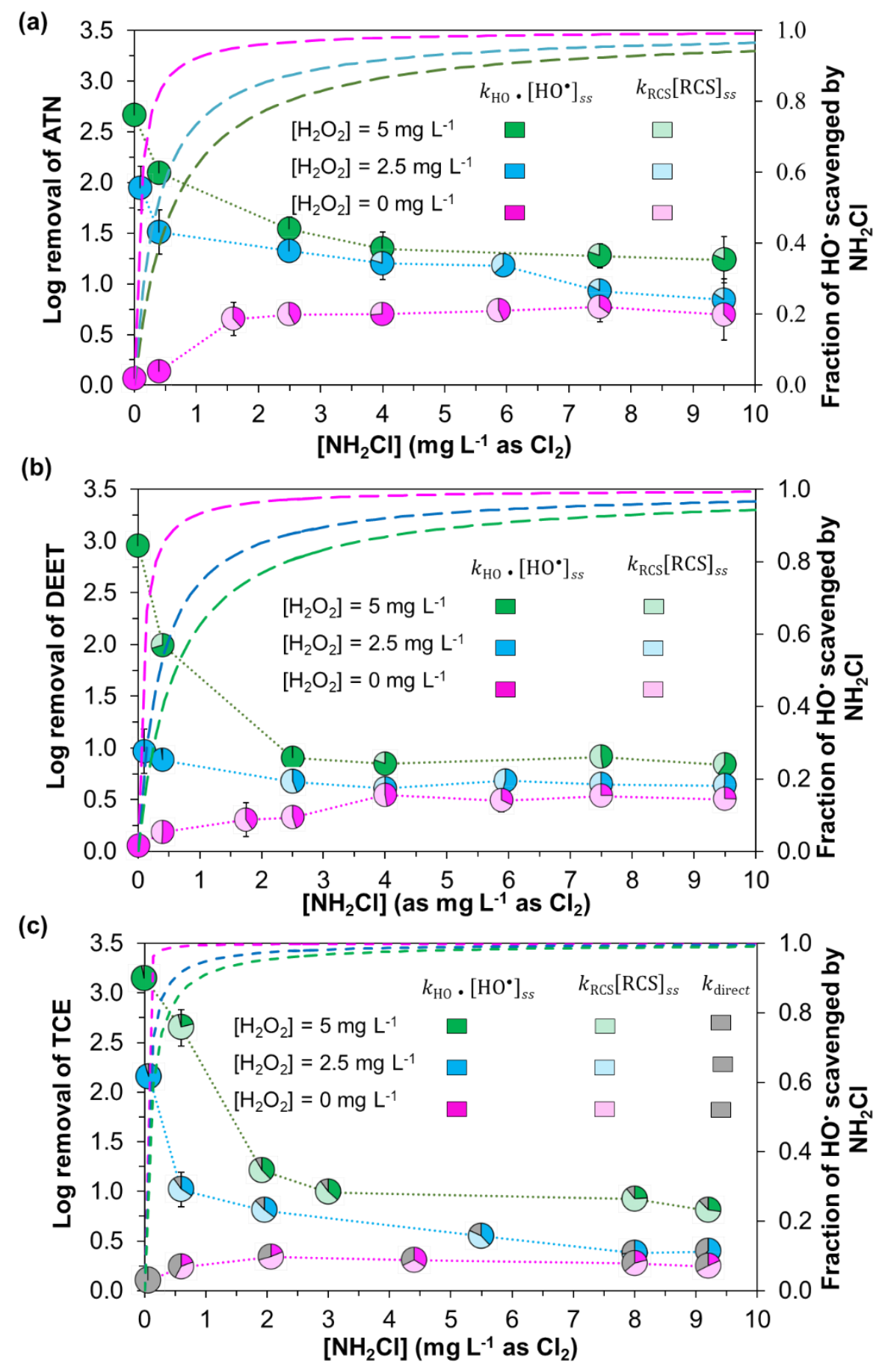

Figure S4. Pilot-scale reactor data showing the effect of $\mathrm{H}_{2} \mathrm{O}_{2}$ and $\mathrm{NH}_{2} \mathrm{Cl}$ concentration on the log removal of trace organic contaminants (a) ATN, (b) DEET, and (c) TCE from RO permeate. Error bars represent the $95 \%$ confidence interval around duplicate analysis. Dashed lines represent scavenging of $\mathrm{HO}^{\circ}$ by $\mathrm{NH}_{2} \mathrm{Cl}$ for three $\mathrm{H}_{2} \mathrm{O}_{2}$ levels. Contribution of reactive species, depicted in pie charts, are based 
on steady-state concentrations of radicals determined using probe compounds. Specifically, contributions of $\mathrm{HO}^{\bullet}$ toward indicator contaminant degradation was calculated as the product of $\left[\mathrm{HO}^{\bullet}\right]_{\mathrm{ss}}$ and known second order rate constant for reaction with $\mathrm{HO}^{\bullet}$ (reported in Table S2). The contribution of RCS was calculated as difference between observed pseudo-first order rate constant and contributions of $\left[\mathrm{HO}^{\circ}\right]_{\mathrm{ss}}$ and direct photolysis, if applicable (Text S1). Note that for ATN and DEET, $\mathrm{Cl}{ }^{\bullet}$ is the driving RCS, whereas, $\mathrm{Cl}_{2}{ }^{*-}$ was the primary RCS responsible for TCE degradation (based on calculations for branching ratio of $\mathrm{Cl}^{\circ}$ ). Experimental conditions: $[\mathrm{TCE}]=8 \mu \mathrm{g} \mathrm{L}^{-1}$; $[\mathrm{ATN}]=[\mathrm{DEET}]=20 \mu \mathrm{g} \mathrm{L}{ }^{-1} ; \mathrm{RO}$ permeate; $\mathrm{pH}=5.8$; total fluence $=850 \pm 50 \mathrm{~mJ} \mathrm{~cm}^{-2}$. 


\section{Text S5. Calculations of branching ratio of $\mathrm{HO}^{\circ}$ and $\mathrm{RCS}$ for all indicator contaminants}

The branching ratio represents the fraction of a reactive species that reacts with the compound of interest with respect to total availability of the reactive species. For example, the branching ratio of $\mathrm{HO}^{\circ}$ is given by Eq $\mathrm{S} 16$ :

$$
\text { Branching ratio of } \mathrm{HO}^{\bullet}=\frac{k_{i}\left[C_{i}\right]}{\sum_{i}^{n} k_{n}\left[C_{n}\right]}
$$

where, $k_{i}$ is the second-order rate constant between $\mathrm{HO}^{\circ}$ and a compound $C_{i}$, and $n$ is the total number of species reacting with $\mathrm{HO}^{\circ}$.

In the current system, $\mathrm{NH}_{2} \mathrm{Cl}$ and $\mathrm{H}_{2} \mathrm{O}_{2}$ are the primary photo-oxidants that undergo photolysis to generate reactive radicals. However, these species can also react with $\mathrm{HO}^{\bullet}$ with second-order rate constants $5.8 \times 10^{8} \mathrm{M}^{-1} \mathrm{~s}^{-1}$ and $2.70 \times 10^{7} \mathrm{M}^{-1} \mathrm{~s}^{-1}$, respectively. ${ }^{26}$ Due to the experimental design and the way $\left[\mathrm{NH}_{2} \mathrm{Cl}\right]$ was controlled in the $\mathrm{RO}$ permeate, $\left[\mathrm{NHCl}_{2}\right]$ was always less than $30 \%$ of $\left[\mathrm{NH}_{2} \mathrm{Cl}\right]$ for $\left[\mathrm{NH}_{2} \mathrm{Cl}\right]<2.5 \mathrm{mg} \mathrm{L}^{-1}$, (expressed as $\mathrm{Cl}_{2}$; all subsequent chloramine concentrations are expressed in $\mathrm{mg}$ $\mathrm{L}^{-1}$ as $\mathrm{Cl}_{2}$ ) - the typical concentration of $\mathrm{NH}_{2} \mathrm{Cl}$ in $\mathrm{RO}$ permeate- due to quenching by sodium sulfite. For $\left[\mathrm{NH}_{2} \mathrm{Cl}\right]>2.5 \mathrm{mg} \mathrm{L}^{-1}, \mathrm{NH}_{2} \mathrm{Cl}$ was added to $\mathrm{RO}$ permeate using a $\mathrm{NH}_{2} \mathrm{Cl}$ stock solution prepared in lab, which contained less than $5 \% \mathrm{NHCl}_{2}$. Furthermore, the reactivity of $\mathrm{NHCl}_{2}$ with $\mathrm{HO}^{\circ}\left(k^{\prime \prime}=2.4 \times\right.$ $10^{8} \mathrm{M}^{-1} \mathrm{~s}^{-1}$ ) was $c a .50 \%$ lower than that of $\mathrm{NH}_{2} \mathrm{Cl}$. Thus, the maximum scavenging of $\mathrm{NHCl}_{2}$ towards $\mathrm{HO}$ branching was less than $10 \%$. Hence, the role of dichloramine $\left(\mathrm{NHCl}_{2}\right)$ as sink of $\mathrm{HO}^{\circ}$ was ignored due to the low concentration of $\mathrm{NHCl}_{2}$ with respect to $\mathrm{NH}_{2} \mathrm{Cl}$.

$$
\begin{array}{lr}
\mathrm{HO}^{\bullet}+\mathrm{NH}_{2} \mathrm{Cl} \rightarrow \mathrm{NHCl}^{\bullet}+\mathrm{H}_{2} \mathrm{O} & \text { Reaction S6a } \\
\mathrm{HO}^{\bullet}+\mathrm{NHCl}_{2} \rightarrow \mathrm{NCl}_{2}^{\bullet}+\mathrm{H}_{2} \mathrm{O} & \text { Reaction S6b } \\
\mathrm{HO}^{\bullet}+\mathrm{H}_{2} \mathrm{O}_{2} \rightarrow \mathrm{H}_{2} \mathrm{O}+\mathrm{HO}_{2}^{\bullet} & \text { Reaction S7 }
\end{array}
$$

At $\mathrm{pH}$ ranges relevant to this system, $\mathrm{HO}_{2}{ }^{\circ}$ is a relatively non-reactive specie. The reaction of $\mathrm{HO}^{\bullet}$ with $\mathrm{Cl}^{-}$present in the $\mathrm{RO}$ permeate generates $\mathrm{HOCl}^{--}\left(k^{\prime \prime}=4.3 \times 10^{9} \mathrm{M}^{-1} \mathrm{~s}^{-1}\right)$ that has a very fast 
decomposition reaction (Reaction $\mathrm{S} 9, k^{\prime}=6.1 \times 10^{9} \mathrm{~s}^{-1}$ ) that reforms $\mathrm{HO}^{\cdot} \cdot{ }^{27} \mathrm{Hence}, \mathrm{Cl}^{-}$was not considered a significant sink for $\mathrm{HO}^{\circ}$.

$\mathrm{HO}^{\bullet}+\mathrm{Cl}^{-} \rightarrow \mathrm{HOCl}^{\bullet-}$

Reaction S8

$\mathrm{HOCl}^{\bullet-} \rightarrow \mathrm{HO}^{\bullet}+\mathrm{Cl}^{-}$

Reaction S9

Other significant sinks for $\mathrm{HO}^{*}$ include total carbonate $\left(\mathrm{CO}_{3}{ }^{2-}\right)$. However, the concentration of total carbonate in $\mathrm{RO}$ permeate is low $\left(\sim 8 \mathrm{mg} \mathrm{L}^{-1}\right)$, and at $\mathrm{pH}$ values lower than 5.8 , exists as bicarbonate $\left(\mathrm{HCO}_{3}^{-}\right)$. Given that reactivity of $\mathrm{HO}^{-}$with $\mathrm{HCO}_{3}^{-}\left(k^{\prime \prime} \mathrm{HCO}_{-, \mathrm{HO}}=8.5 \times 10^{6} \mathrm{M}^{-1} \mathrm{~s}^{-1}\right)$ is significantly lower than that $\mathrm{CO}_{3}{ }^{2-}\left(k^{\prime \prime} \mathrm{CO}_{3-2, \mathrm{HO}}=3.9 \times 10^{8} \mathrm{M}^{-1} \mathrm{~s}^{-1}\right)^{28}$, scavenging by total carbonate was low. For example, at $\left[\mathrm{NH}_{2} \mathrm{Cl}\right]=2.5 \mathrm{mg} \mathrm{L}^{-1}$ and $\left[\mathrm{H}_{2} \mathrm{O}_{2}\right]=2.5 \mathrm{mg} \mathrm{L}^{-1}$, the branching ratio of $\mathrm{HO}^{\bullet}$ with carbonate was less than $2 \%$. Similarly, total organic carbon (TOC, $k^{\prime \prime}=10^{8} \mathrm{M}^{-1} \mathrm{~s}^{-1}$ ) was ignored due to low presence in RO permeate $\left(\sim 47 \mathrm{ug} \mathrm{L}^{-1}\right)$. Note that $\left[\mathrm{Br}^{-}\right]$was below detection limit $\left(0.1 \mathrm{mg} \mathrm{L}^{-1}\right)$ and was expected to be three order of magnitude lower than $\left[\mathrm{Cl}^{-}\right]$based on history of RO permeate characteristics obtained from full-scale systems. Thus, the major sinks of $\mathrm{HO}^{\circ}$ were $\mathrm{H}_{2} \mathrm{O}_{2}, \mathrm{NH}_{2} \mathrm{Cl}$, and probe and model compounds. The concentration of photo-oxidants was almost two orders of magnitude greater than that of probes or trace contaminants. The branching ratio of $\mathrm{HO}^{\bullet}$ for various experimental conditions with 1,4-D, ATN, CAF, TCE, and DEET are shown in top panel of Figures S5-S9.

Similarly, the branching ratio for RCS in the system can be evaluated. Note that the RCS in the system are generated from reaction of $\mathrm{Cl}^{-}$resulting from the photolysis of chloramine species. The major sinks of $\mathrm{Cl}^{\cdot}$ are chloride ion $\left(\mathrm{Cl}^{-}, k^{\prime \prime}=6.9 \times 10^{9} \mathrm{M}^{-1} \mathrm{~s}^{-1}\right), \mathrm{NH}_{2} \mathrm{Cl}\left(k^{\prime \prime}=10^{7} \mathrm{M}^{-1} \mathrm{~s}^{-1}\right), \mathrm{H}_{2} \mathrm{O}_{2}\left(k^{\prime \prime}=10^{7}\right.$ $\left.\mathrm{M}^{-1} \mathrm{~s}^{-1}\right)$ and indicator compounds $\left(k^{\prime \prime}=10^{5}-10^{9} \mathrm{M}^{-1} \mathrm{~s}^{-1}\right)$. Note that since $\mathrm{Cl}^{\bullet}$ is analogous to $\mathrm{HO}{ }^{\bullet}$ in reactivity, the rate constant for reaction of $\mathrm{Cl}^{\circ}$ with oxidants was based off their known second-order rate constants for reaction with $\mathrm{HO}^{*} .^{5}$

$\mathrm{Cl}^{\bullet}+\mathrm{Cl}^{-} \rightarrow \mathrm{Cl}_{2}^{\cdot-}$

Reaction S10 
For typical oxidant conditions, $\mathrm{NH}_{2} \mathrm{Cl}$ and $\mathrm{Cl}^{-}$account for almost $90 \%$ of the $\mathrm{Cl}^{\circ}$ consumption. The subsequently formed $\mathrm{NHCl}^{*}$ radical is non-reactive with the indicator compounds; however, $\mathrm{Cl}_{2}{ }^{-}$is a relevant RCS despite low reactivity and high selectivity, due to high steady-state concentrations. In the current system, $\mathrm{Cl}^{-}$outcompetes other sinks of $\mathrm{Cl}^{*}$ (branching ratio $>85 \%$ ), resulting in high steadystate concentrations of $\mathrm{Cl}_{2}{ }^{-}$. Previous literature suggests that steady-state concentrations of $\mathrm{Cl}_{2}{ }^{-{ }^{-}}$in systems containing $\mathrm{Cl}^{-}$may be one to two order of magnitude greater than that of $\mathrm{Cl}^{\cdot}{ }^{5-7}$ Thus, for compounds with low reactivity with $\mathrm{Cl}^{\circ}$ and $\mathrm{Cl}_{2}{ }^{\bullet-}\left(k^{\prime \prime}<10^{8} \mathrm{M}^{-1} \mathrm{~s}^{-1}\right), \mathrm{Cl}_{2}{ }^{-*}$ is the expected RCS to drive degradation. These include 1,4-D and TCE. For $\mathrm{Cl}_{2}{ }^{\circ-}$, the major sinks are indicator compounds, and oxidants $\left(k^{\prime \prime}=10^{5}-10^{8} \mathrm{M}^{-1} \mathrm{~s}^{-1)}\right.$. For compounds such as ATN, CAF, and DEET with high reactivity with RCS $\left(k^{\prime \prime} \sim 10^{9} \mathrm{M}^{-1} \mathrm{~s}^{-1}\right), \mathrm{Cl}^{\bullet}$ is the dominant RCS.

$\mathrm{Cl}_{2}^{--}+\mathrm{NH}_{2} \mathrm{Cl} \rightarrow \mathrm{NHCl}^{\bullet}+\mathrm{H}^{+}+2 \mathrm{Cl}^{-}$ Reaction S13

$\mathrm{Cl}_{2}^{--}+\mathrm{H}_{2} \mathrm{O}_{2} \rightarrow \mathrm{HO}_{2}^{\cdot}+\mathrm{H}^{+}+2 \mathrm{Cl}^{-}$ Reaction S14

Reactivity of $\mathrm{Cl}_{2}{ }^{\circ-}$ with water is low $\left(k^{\prime \prime}<10^{-3} \mathrm{~s}^{-1}\right) .{ }^{5}$ Thus, the major sinks are oxidants and indicator compound. The branching ratio of relevant RCS for various experimental conditions with 1,4-D, ATN, CAF, TCE, and DEET are shown in bottom panel of Figures S5-S9. 


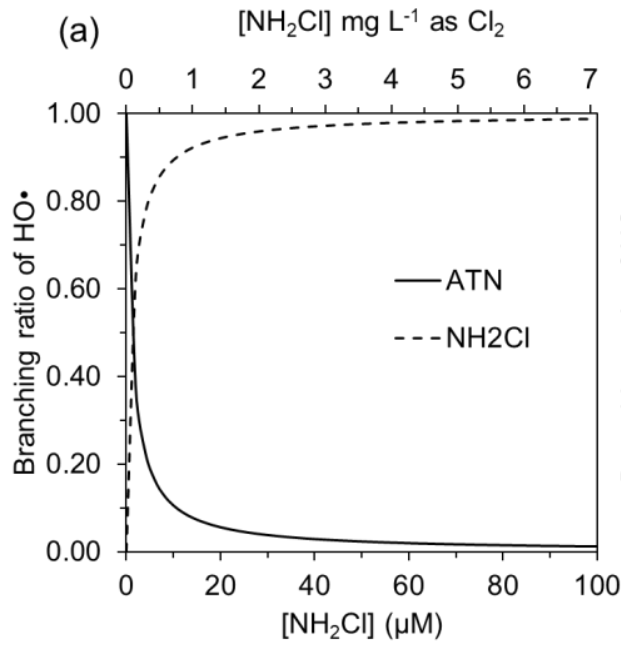

(b) $\quad\left[\mathrm{NH}_{2} \mathrm{Cl}\right] \mathrm{mg} \mathrm{L}^{-1}$ as $\mathrm{Cl}_{2}$

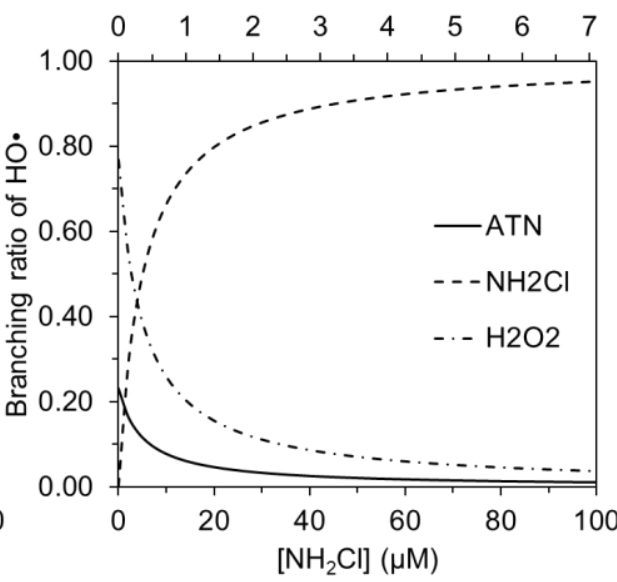

(d) $\quad\left[\mathrm{NH}_{2} \mathrm{Cl}\right] \mathrm{mg} \mathrm{L}^{-1}$ as $\mathrm{Cl}_{2}$

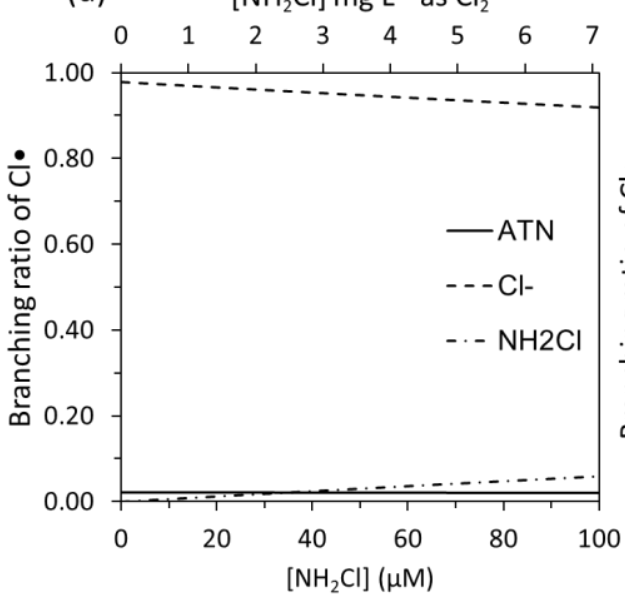

(e)

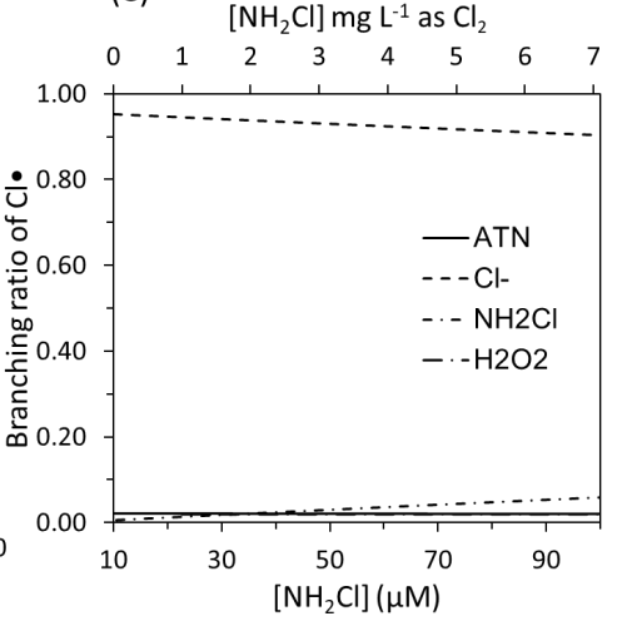

(c)

[ $\left.\mathrm{NH}_{2} \mathrm{Cl}\right] \mathrm{mg} \mathrm{L}^{-1}$ as $\mathrm{Cl}_{2}$

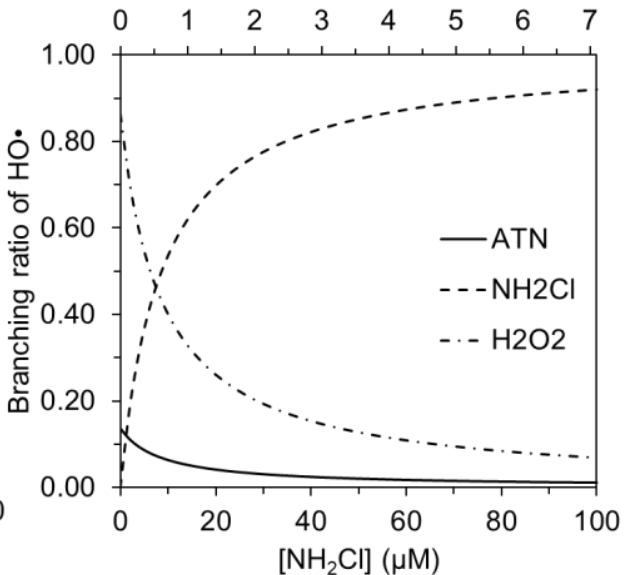

(f)

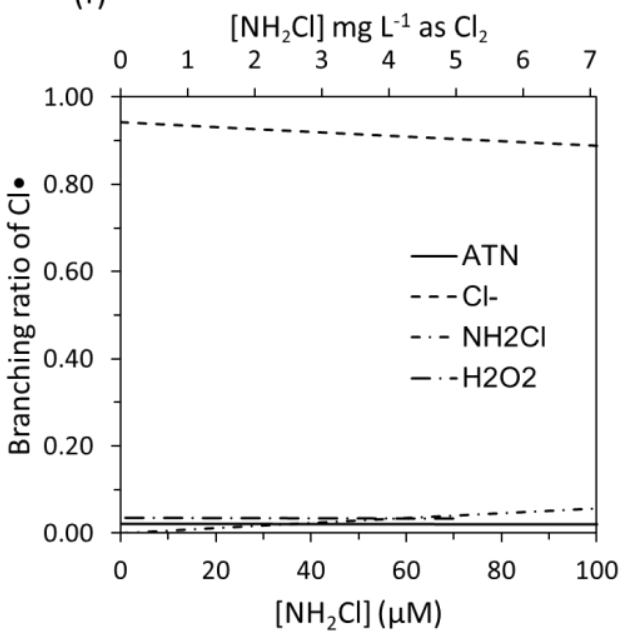

Figure S5. Branching ratio of $\mathrm{HO}^{*}$ and $\mathrm{Cl}^{\bullet}$ for ATN degradation in $\mathrm{UV}_{-} \mathrm{H}_{2} \mathrm{O}_{2}-\mathrm{NH}_{2} \mathrm{Cl}$ for three doses of $\mathrm{H}_{2} \mathrm{O}_{2}$, (a,d) $0 \mathrm{mg} \mathrm{L}^{-1}$, (b,e) 2.5 $\mathrm{mg} \mathrm{L}{ }^{-1}$, and (c.f) $5 \mathrm{mg} \mathrm{L}^{-1}$. Experimental conditions: $[\mathrm{ATN}]=20 \mu \mathrm{g} \mathrm{L}-1$; RO permeate; $\mathrm{pH}=5.8$; total fluence $=850 \pm 50 \mathrm{~mJ} \mathrm{~cm}^{-2}$. 

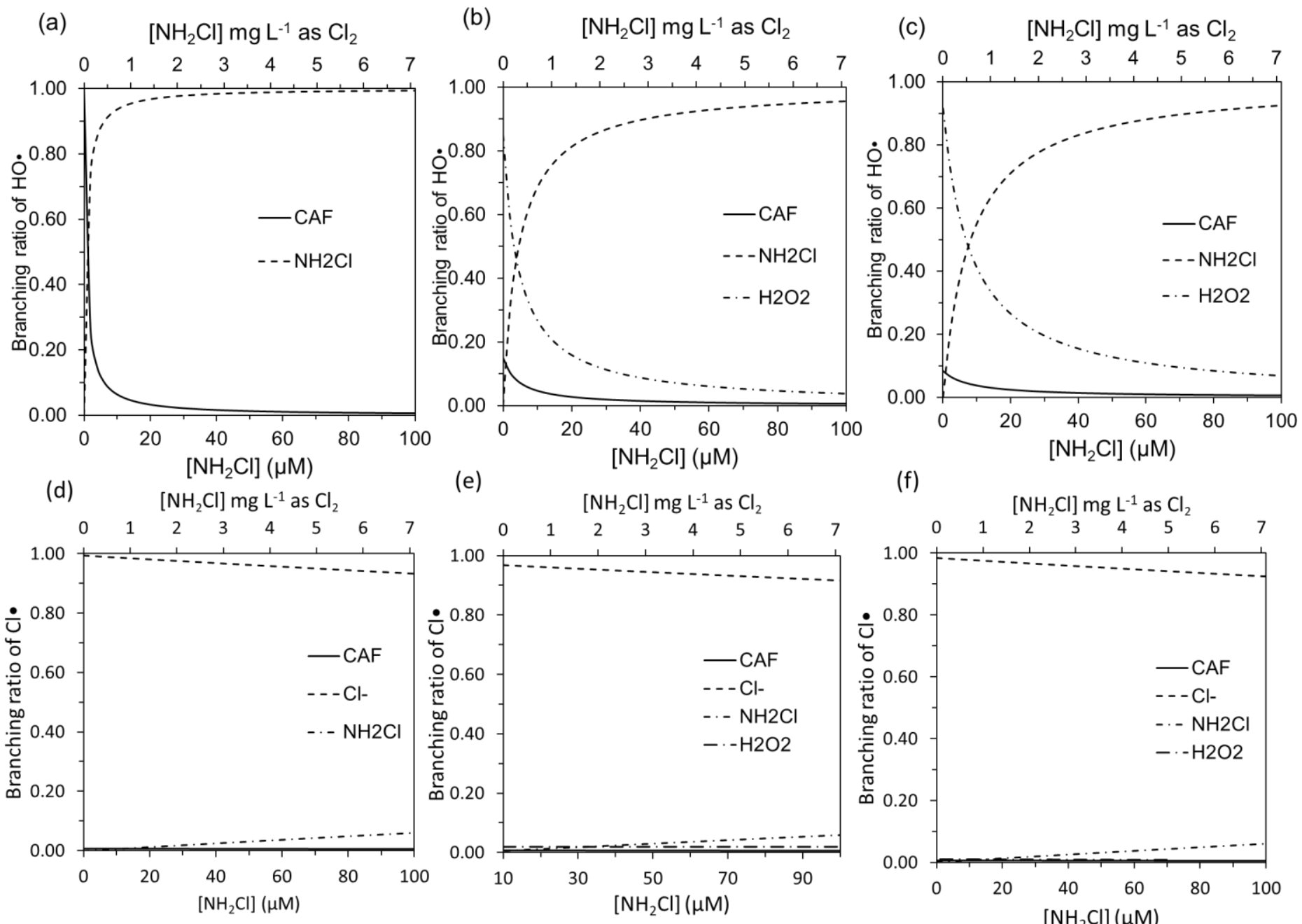

(e)
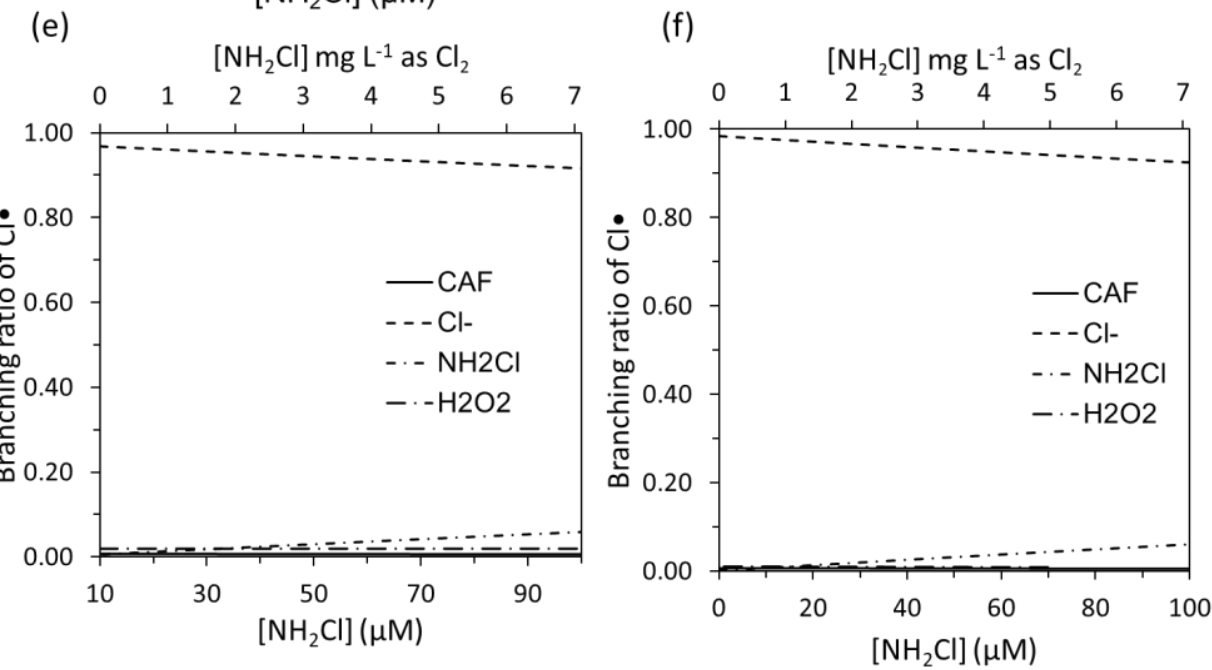

Figure S6. Branching ratio of $\mathrm{HO}^{\bullet}$ and $\mathrm{Cl}^{\bullet}$ for $\mathrm{CAF}$ degradation in $\mathrm{UV}-\mathrm{H}_{2} \mathrm{O}_{2}-\mathrm{NH}_{2} \mathrm{Cl}$ for three doses of $\mathrm{H}_{2} \mathrm{O}_{2}$, (a,d) 0 mg L $\mathrm{m}^{-1}$, (b,e) 2.5 $\mathrm{mg} \mathrm{L}{ }^{-1}$, and (c.f) $5 \mathrm{mg} \mathrm{L}^{-1}$. Experimental conditions: $[\mathrm{CAF}]=100 \mu \mathrm{g} \mathrm{L}^{-1}$; RO permeate; $\mathrm{pH}=5.8$; total fluence $=850 \pm 50 \mathrm{~mJ} \mathrm{~cm}^{-2}$. 
(a)

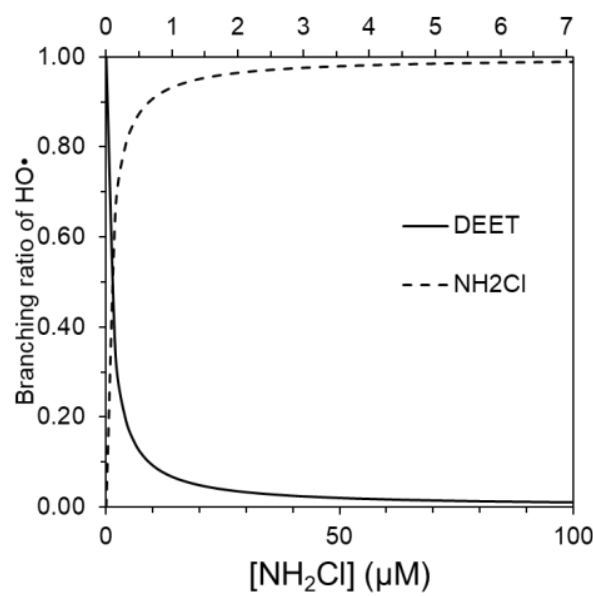

(d) $\left[\mathrm{NH}_{2} \mathrm{Cl}\right] \mathrm{mg} \mathrm{L}^{-1}$ as $\mathrm{Cl}_{2}$

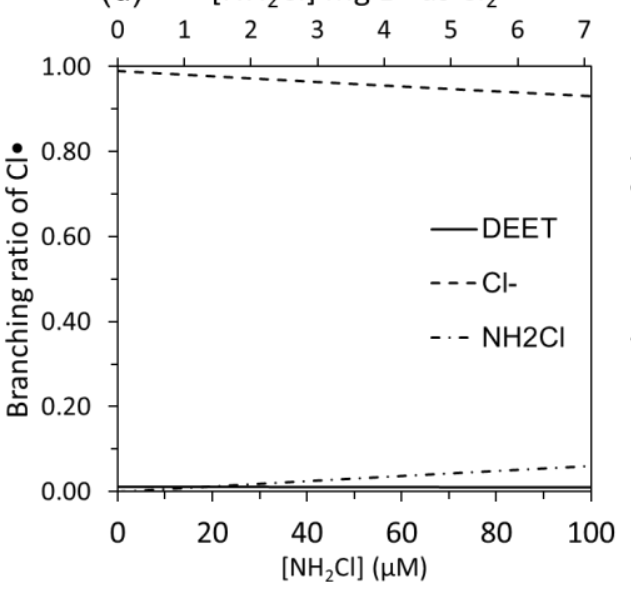

(b)

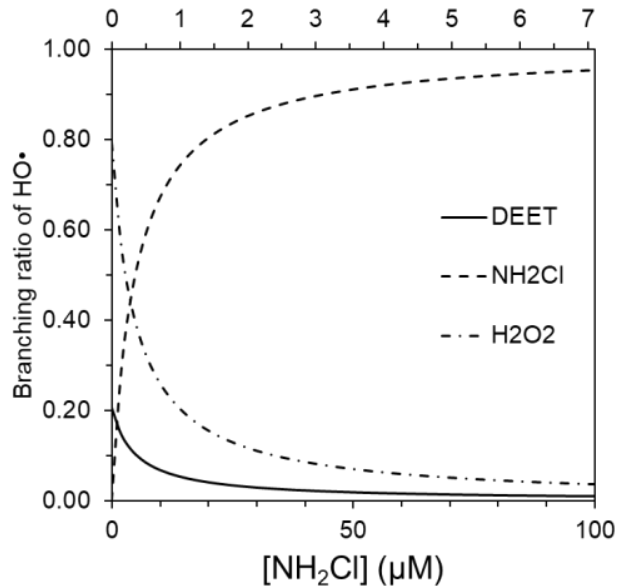

(e) $\left[\mathrm{NH}_{2} \mathrm{Cl}\right] \mathrm{mg} \mathrm{L}^{-1}$ as Cl $\mathrm{Cl}_{2}$

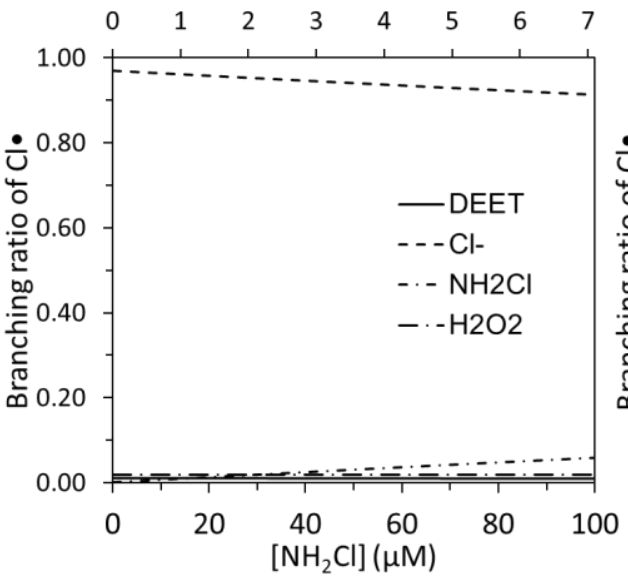

(c) $\left[\mathrm{NH}_{2} \mathrm{Cl}\right] \mathrm{mg} \mathrm{L}^{-1}$ as $\mathrm{Cl}_{2}$

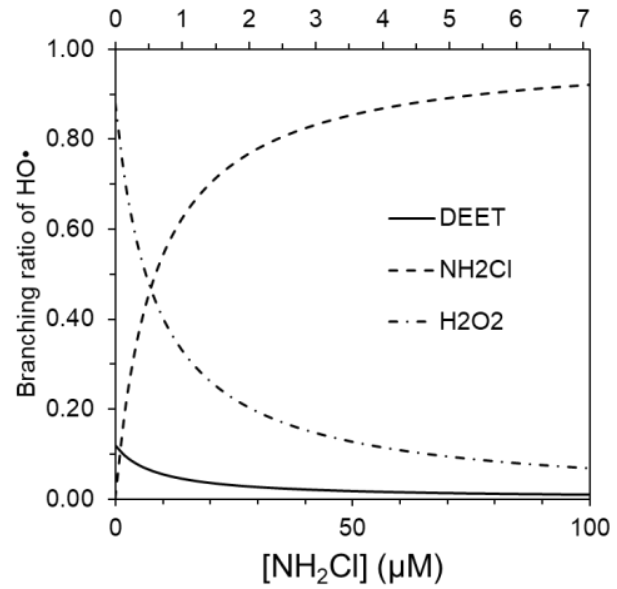

(f)

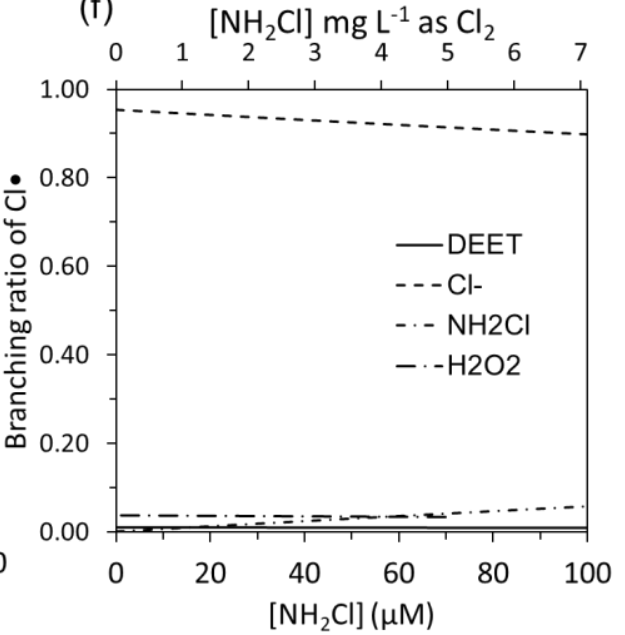

Figure S7. Branching ratio of $\mathrm{HO}^{*}$ and $\mathrm{Cl}^{*}$ for DEET degradation in $\mathrm{UV}^{-} \mathrm{H}_{2} \mathrm{O}_{2}-\mathrm{NH}_{2} \mathrm{Cl}$ for three doses of $\mathrm{H}_{2} \mathrm{O}_{2}$, (a,d) 0 mg L ${ }^{-1}$, (b.e) 2.5 $\mathrm{mg} \mathrm{L}^{-1}$, and (c.f) $5 \mathrm{mg} \mathrm{L}^{-1}$. Experimental conditions: [DEET] $=20 \mu \mathrm{g} \mathrm{L}^{-1}$; RO permeate; $\mathrm{pH}=5.8$; total fluence $=850 \pm 50 \mathrm{~mJ} \mathrm{~cm}^{-2}$. 


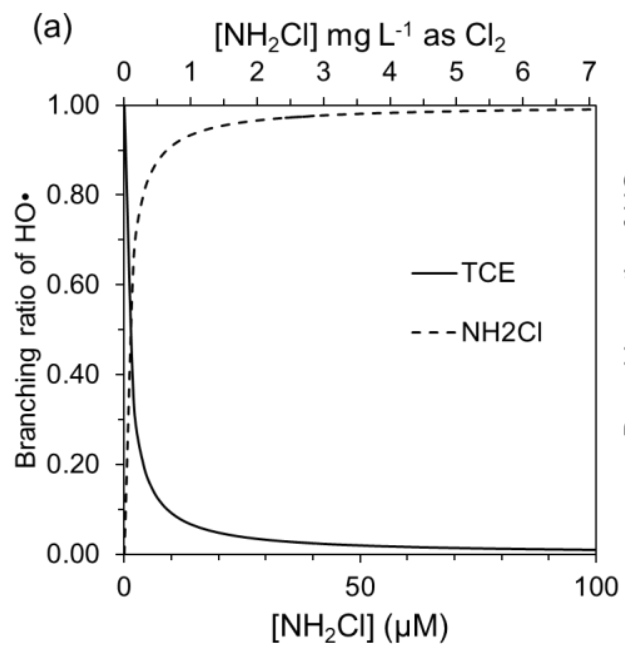

(b) ${ }_{0} \quad \begin{aligned} & \left.\mathrm{NH}_{2} \mathrm{Cl}\right] \mathrm{mg} \mathrm{L}^{-1} \\ & \mathrm{~N}_{3}\end{aligned} \underset{4}{\mathrm{C} \mathrm{Cl}_{2}}$

(c) $\left[\mathrm{NH}_{2} \mathrm{Cl}\right] \mathrm{mg} \mathrm{L}^{-1}$ as $\mathrm{Cl}_{2}$
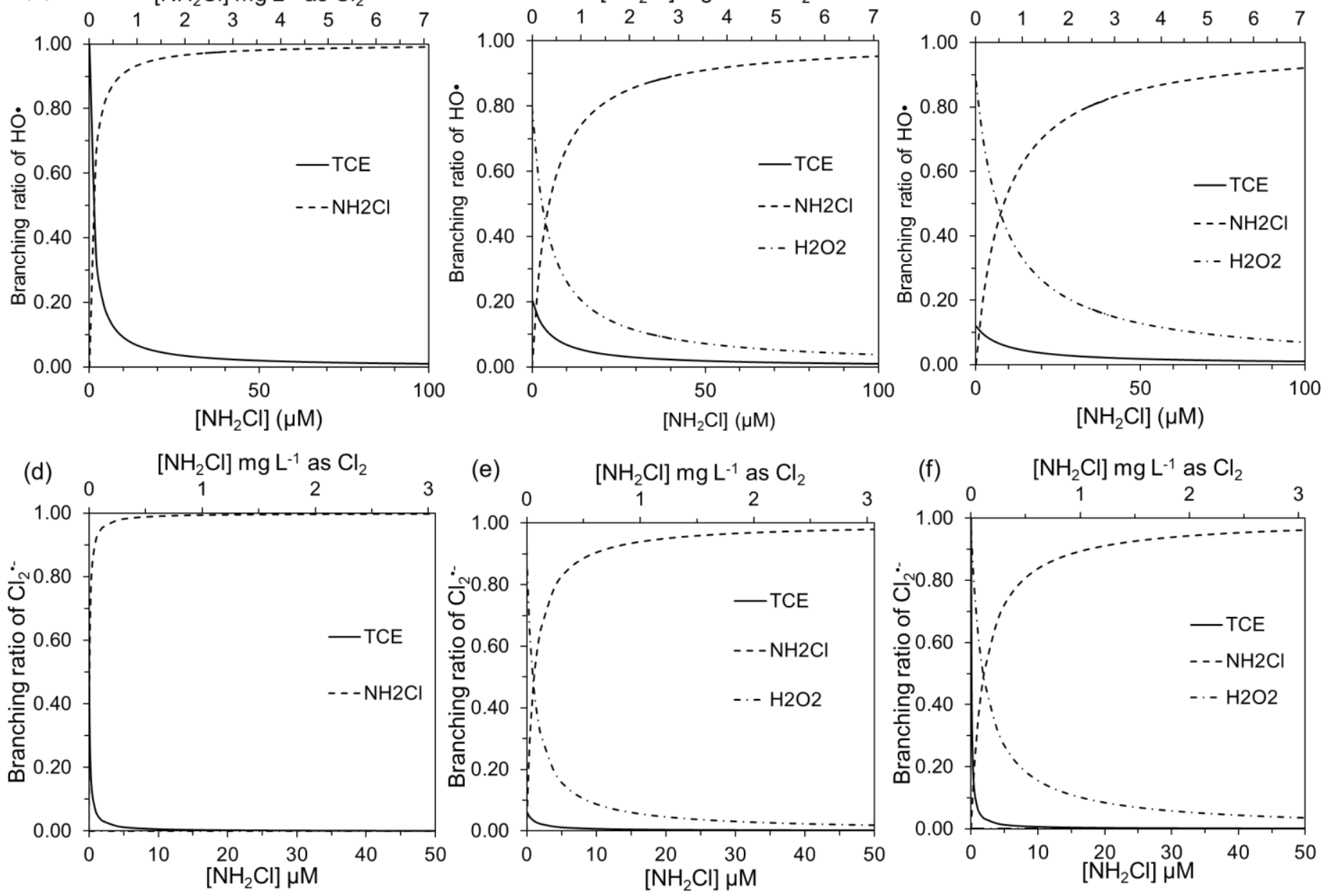

(e) $\quad\left[\mathrm{NH}_{2} \mathrm{Cl}\right] \mathrm{mg} \mathrm{L}^{-1}$ as $\mathrm{Cl}_{2}$
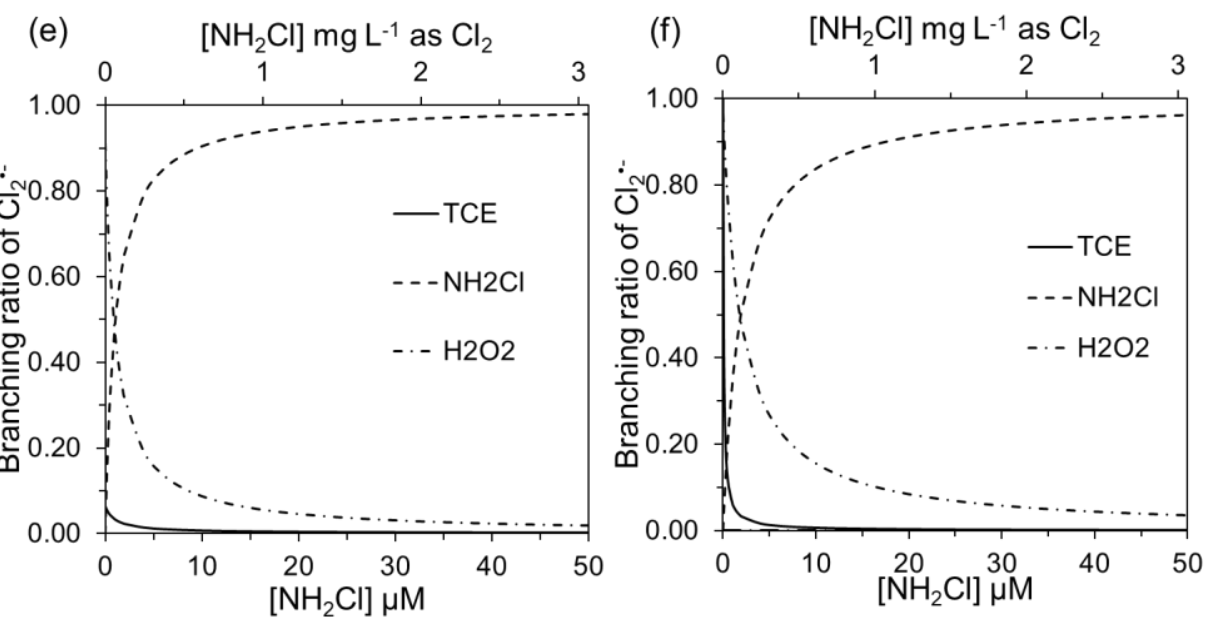

Figure S8. Branching ratio of $\mathrm{HO}^{\circ}$ and $\mathrm{Cl}_{2}{ }^{\circ}$ for TCE degradation in $\mathrm{UV}-\mathrm{H}_{2} \mathrm{O}_{2}-\mathrm{NH}_{2} \mathrm{Cl}$ for three doses of $\mathrm{H}_{2} \mathrm{O}_{2}$, (a,d) 0 mg L ${ }^{-1}$, (b,e) 2.5 $\mathrm{mg} \mathrm{L}^{-1}$, and (c,f) $5 \mathrm{mg} \mathrm{L}^{-1}$. Experimental conditions: $[\mathrm{TCE}]=8 \mu \mathrm{g} \mathrm{L}-1$; RO permeate; $\mathrm{pH}=5.8$; total fluence $=850 \pm 50 \mathrm{~mJ} \mathrm{~cm}^{-2}$. 
(a)
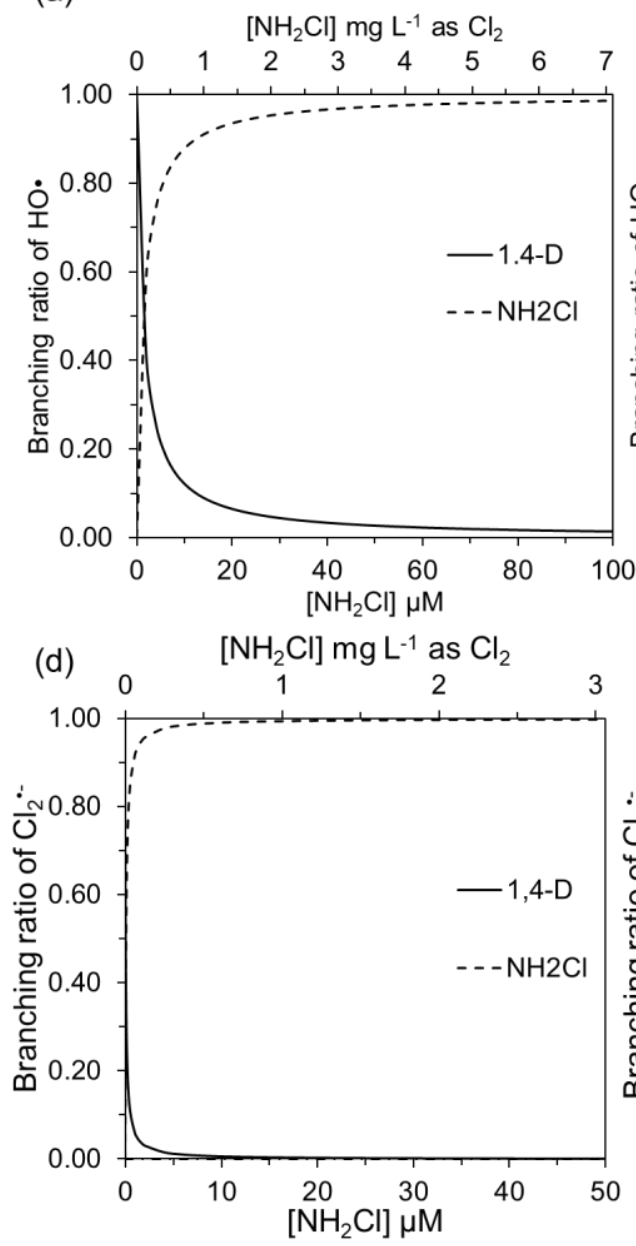

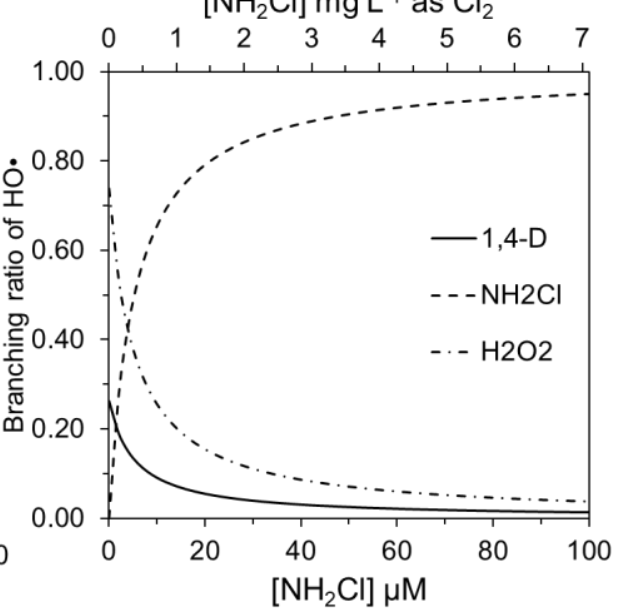

(e) $\quad\left[\mathrm{NH}_{2} \mathrm{Cl}\right] \mathrm{mg} \mathrm{L}^{-1}$ as $\mathrm{Cl}_{2}$

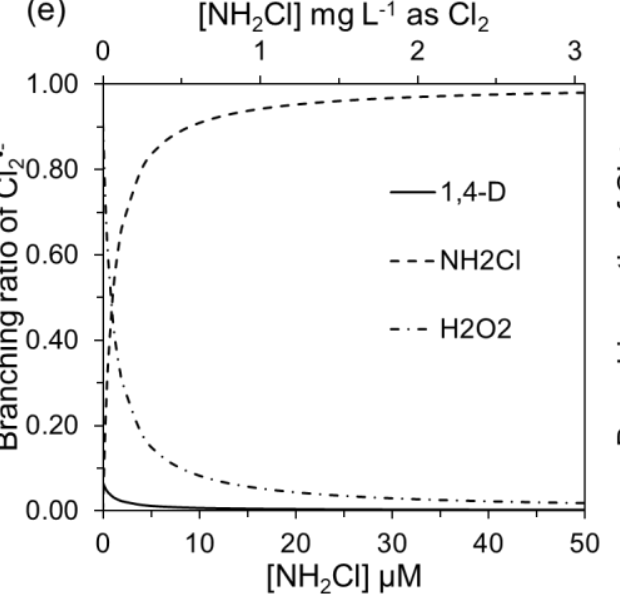

(c)

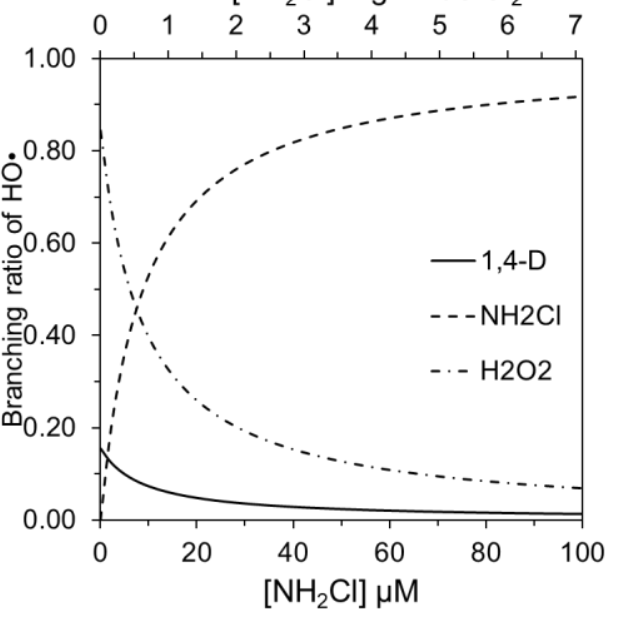

(f)

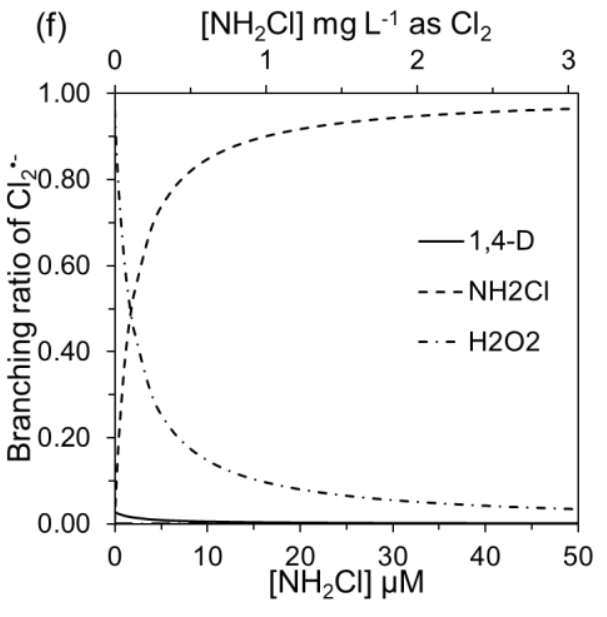

Figure S9. Branching ratio of $\mathrm{HO}^{\circ}$ and $\mathrm{Cl}_{2}{ }^{\circ}$ - for 1,4-D degradation in $\mathrm{UV}_{-} \mathrm{H}_{2} \mathrm{O}_{2}-\mathrm{NH}_{2} \mathrm{Cl}$ for three doses of $\mathrm{H}_{2} \mathrm{O}_{2}$, (a.d) 0 mg L ${ }^{-1}$, (b,e)

$2.5 \mathrm{mg} \mathrm{L}^{-1}$, and (c,f) $5 \mathrm{mg} \mathrm{L}^{-1}$. Experimental conditions: $[1,4-\mathrm{D}]=20 \mu \mathrm{g} \mathrm{L}^{-1} ; \mathrm{RO}$ permeate; $\mathrm{pH}=5.8$; total fluence $=850 \pm 50 \mathrm{~mJ} \mathrm{~cm}^{-2}$. 

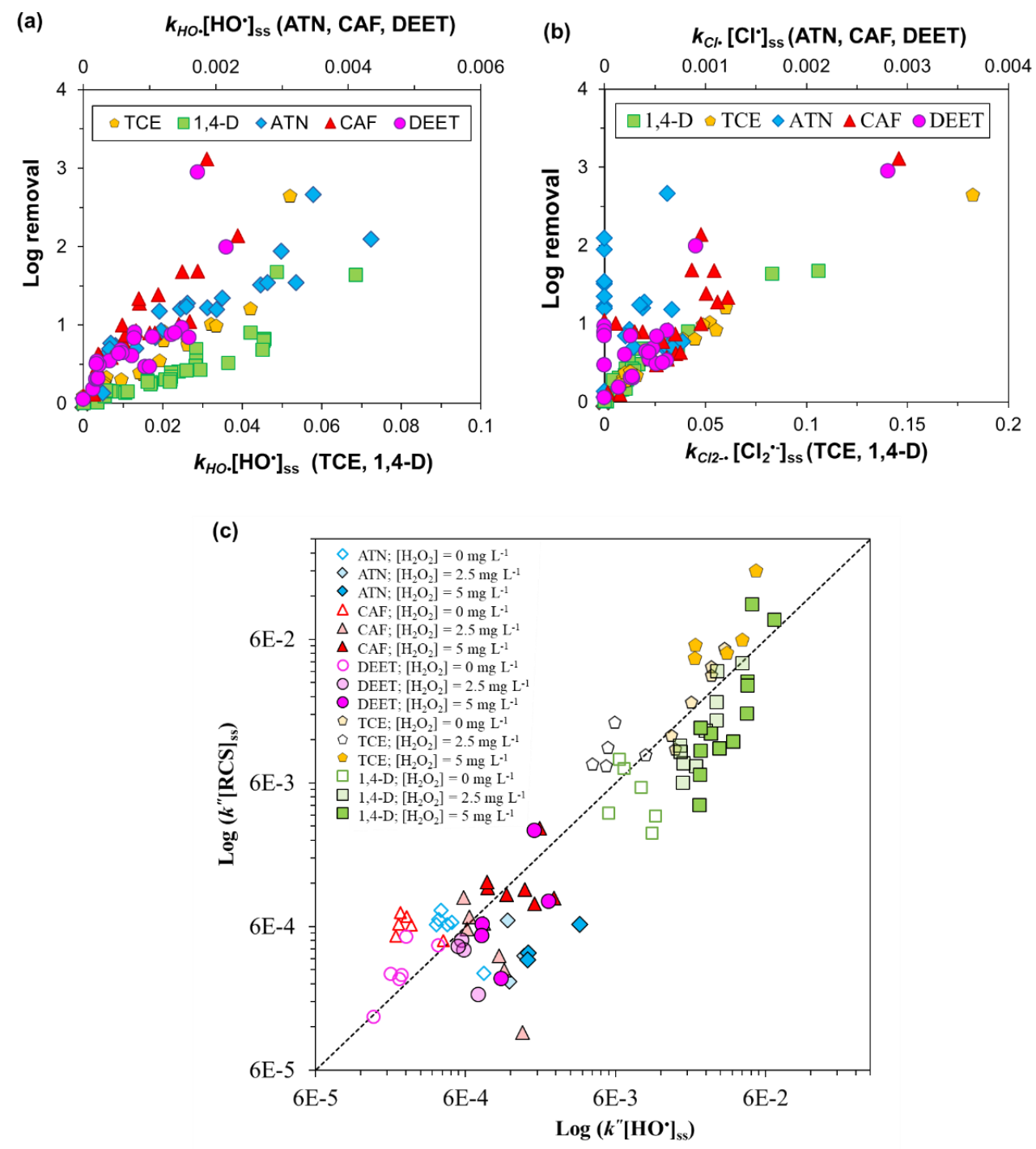

Figure S10. Correlation between log removal and contribution of (a) $\mathrm{HO}^{\bullet}$ and (b) RCS for degradation of ATN, CAF, DEET, TCE, and 1,4-D for all conditions tested in this study; (c) plot comparing contribution of $\mathrm{HO}^{\circ}$ and RCS for the removal of ATN, CAF, DEET, TCE, and 1,4-D from RO permeate by UV-NH${ }_{2} \mathrm{Cl}$ AOP in the presence of $0,2.5$, and $5 \mathrm{mg} \mathrm{L}^{-1}$. The contribution of RCS was calculated as difference between observed pseudo-first order rate constant and product of $\left[\mathrm{HO}^{\circ}\right]_{\mathrm{ss}}$ and second-order rate constant for reaction of trace contaminant with $\mathrm{HO}^{\bullet}$. Experimental conditions: [CAF] $=100 \mu \mathrm{g} \mathrm{L}{ }^{-1}$; $[\mathrm{TCE}]=8 \mu \mathrm{g}$ $\mathrm{L}^{-1} ;[\mathrm{ATN}]=[\mathrm{DEET}]=[1,4-\mathrm{D}]=20 \mu \mathrm{g} \mathrm{L}-1$ RO permeate; $\mathrm{pH}=5.8 ;$ total fluence $=850 \pm 50 \mathrm{~mJ} \mathrm{~cm}^{-2}$. 


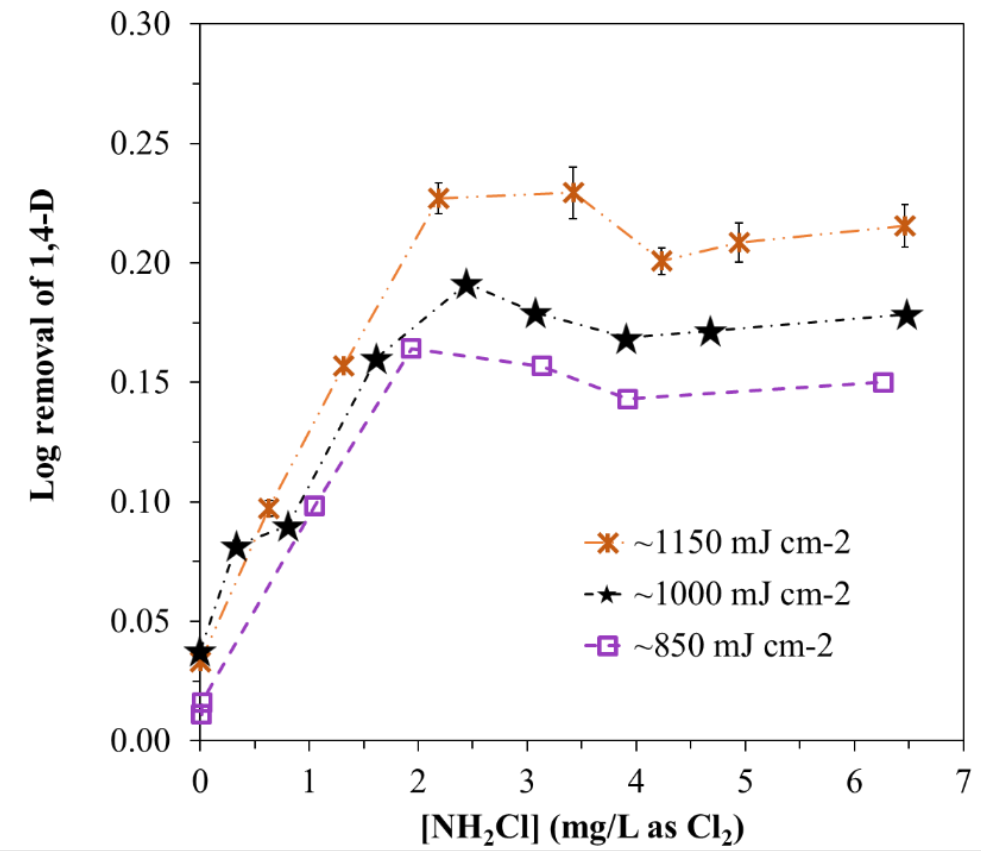

Figure S11. Plot showing log removal of 1,4-D with increase in $\mathrm{NH}_{2} \mathrm{Cl}$, for three different fluence conditions, in absence of $\mathrm{H}_{2} \mathrm{O}_{2}$. Experimental conditions: $\mathrm{RO}$ permeate; [1,4-D] $=20 \mu \mathrm{g} \mathrm{L}^{-1} ; \mathrm{pH}=5.8$. 


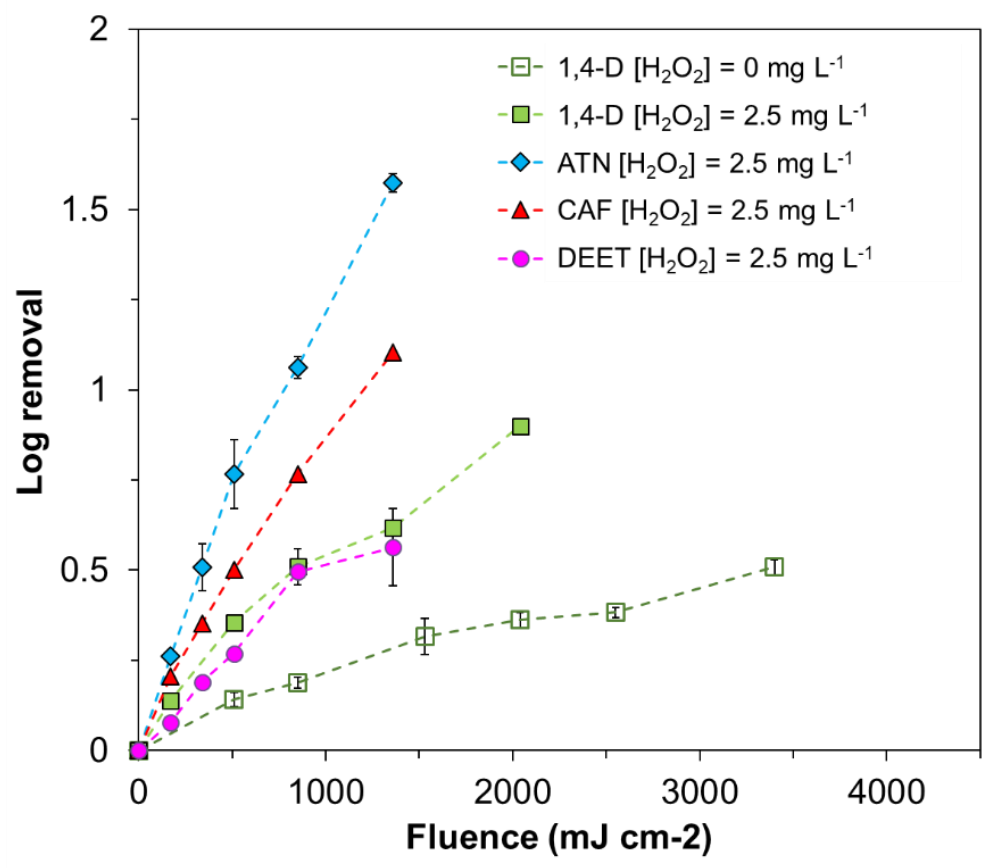

Figure S12. Trends showing the effect of fluence on the log removal of trace contaminants in presence of $2.5 \mathrm{mg} \mathrm{L}^{-1} \mathrm{H}_{2} \mathrm{O}_{2}$ and $2.5 \mathrm{mg} \mathrm{L}^{-1} \mathrm{NH}_{2} \mathrm{Cl}$. For 1,4-D, log removal was also tested in absence of $\mathrm{H}_{2} \mathrm{O}_{2}$. Experiments were conducted on bench-scale reactor under conditions mimicking pilot- and full-scale reactors. Details on bench-scale reactor, and comparison with pilot-scale reactor are provided in Text S4. Experimental conditions: $[\mathrm{CAF}]=100 \mu \mathrm{g} \mathrm{L}-1 ;[\mathrm{ATN}]=[\mathrm{DEET}]=[1,4-\mathrm{D}]=20 \mu \mathrm{g} \mathrm{L}{ }^{-1} ; \mathrm{RO}$ permeate; $\mathrm{pH}=5.8$. 


\section{Text S6. Impact of pathlength on log removal of 1,4-D}

To improve degradation of trace organic contaminants in a UV-AOP system, an increase in effective UV fluence by increasing pathlength was investigated. For RO permeate of known transmissivity, the impact of increasing the optical pathlength (by increasing the diameter of cylindrical UV reactor) was modelled based on equations described by others ${ }^{29,30}$. In short, the direct photolysis of oxidants and indicator compounds maybe described by

$\frac{d[\text { compound }]}{d t}=r_{\text {compound }}=-\varepsilon_{254, \text { compound }} \times \frac{\left(1-10^{-a l}\right)}{a l} \times \phi_{254, N H 2 C l} \times I_{o} \times[$ compound $] \quad$ Eq S12 where, $a$ is the absorbance of the solution, and $l$ is the solution depth or optical pathlength. For dilute solutions $(a<0.002)$, Eq S12 can be simplified to Eq S6 by application of Beer's law and Taylor theorem. Alternately, Eq 12 can be further modified to Eq S13 to compare the log removal at various pathlengths.

$\ln \frac{[\text { compound }]}{[\text { compound }]_{0}}=-\varepsilon_{254, \text { compound }} \times \frac{\left(1-10^{-a l}\right)}{a l} \times \phi_{254, N H 2 C l} \times I_{O} \times t$

In general, for $\sim 100 \% \mathrm{UV}$ transmittance at $254 \mathrm{~nm}\left(\mathrm{UVT}_{254}\right)$ of water in a single lamp, axial-flow reactor, the difference between the radius of reactor and radius of lamp housing was the optical pathlength ${ }^{29}$. Based on continuity equation, for reactor length and design flowrate through the reactor (6 gallons per minute), it follows that increasing diameter of reactor decreases the velocity of flow, resulting in greater irradiation time. In these conditions, the increase in optical pathlength will linearly increase photodegradation of oxidants resulting in greater degradation efficiency. However, the typical $\mathrm{UVT}_{254}$ of RO permeate feedwater to the UV-AOP system is $\sim 97 \%$ (based on experimentally observed values), of which chloramines account for more than $95 \%$ of the absorbance $\left(\varepsilon_{254 \mathrm{~nm}}=142 \mathrm{M}^{-1} \mathrm{~cm}^{-1}\right.$ for $\mathrm{NH}_{2} \mathrm{Cl} ; 388 \mathrm{M}^{-1} \mathrm{~cm}^{-1}$ for $\left.\mathrm{NHCl}_{2}\right) .{ }^{31}$ Dissolved organic carbon and $\mathrm{H}_{2} \mathrm{O}_{2}\left(\varepsilon_{254 \mathrm{~nm}}=18.6 \mathrm{M}^{-1} \mathrm{~cm}^{-1}\right)$ provide minimal absorbance and the screening effect was neglected. Thus, for the same irradiation source and 
surface area (inner diameter of reactor), a lower UVT and higher chloramine concentrations in RO permeate, results in a non-linear increase in UV dose (volume normalized UV energy input). Thus, improved log removal efficiency of 1,4-D is observed at higher optical pathlengths (Figure S13). In this study, the predictions are based on 1,4-D removal in UV-AOP pilot reactor at $850 \mathrm{~mJ} \mathrm{~cm}^{-2}$. Note that this discussion is limited to single lamp, axial flow reactors; for multi-bulb reactors, effective optical pathlength is reactor design specific, and is determined based on computation fluid dynamics, and actinometry or biodosimetry. ${ }^{32}$ 

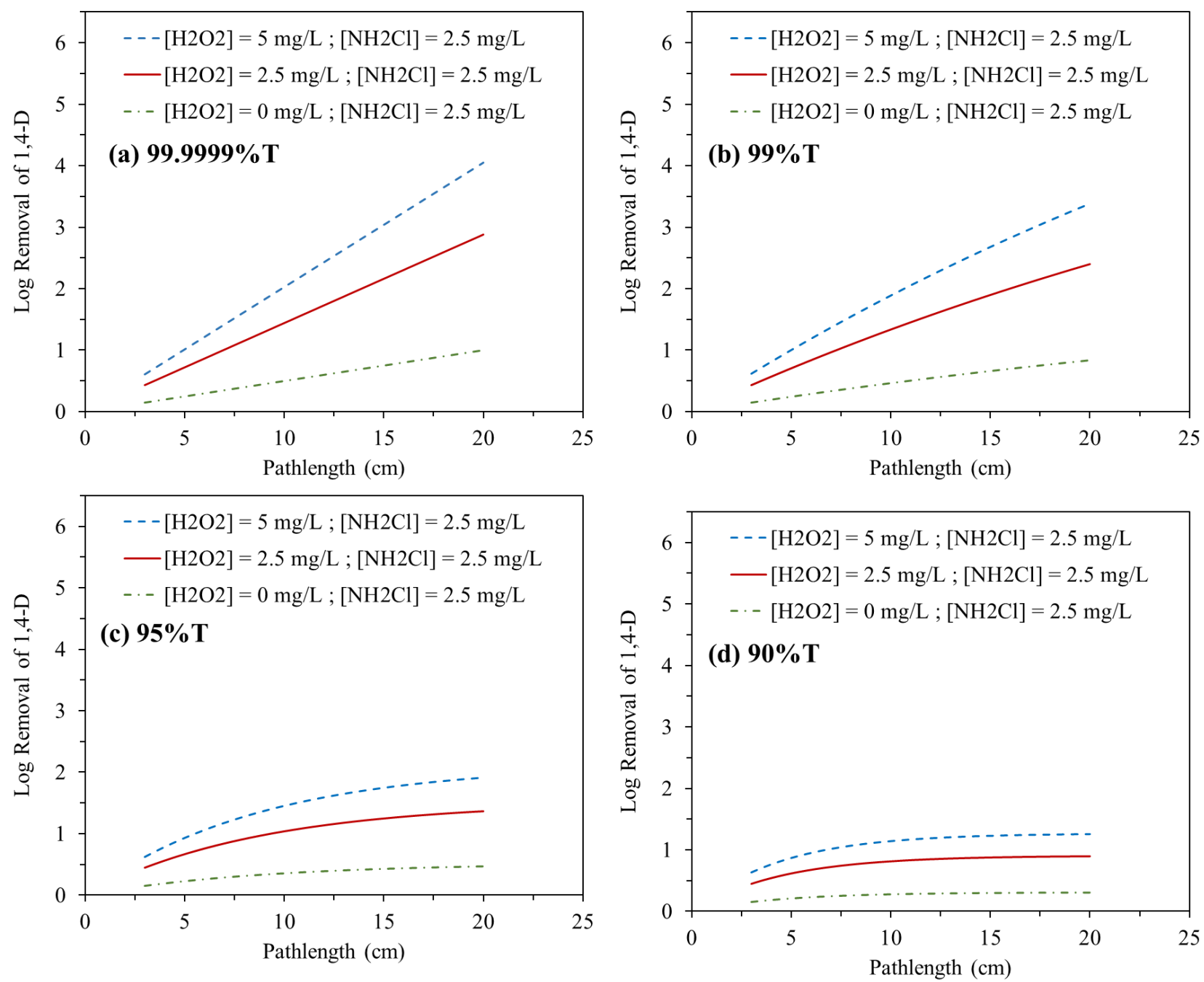

Figure S13. The effect of increasing pathlength of single-lamp axial flow reactor (UV-AOP pilot reactor) on log removal of 1,4-D from RO permeate under various photo-oxidant conditions and decreasing percent transmittance (UVT $254, \% \mathrm{~T}$ ), (a) $99.9999 \% \mathrm{~T}$, (b) $99 \% \mathrm{~T}$, (c) $95 \% \mathrm{~T}$, and (d) $90 \% \mathrm{~T}$. Experimental conditions: $[1,4-\mathrm{D}]=20 \mu \mathrm{g} \mathrm{L}^{-1}$; $\mathrm{RO}$ permeate; $\mathrm{pH}=5.8$. 
(a)

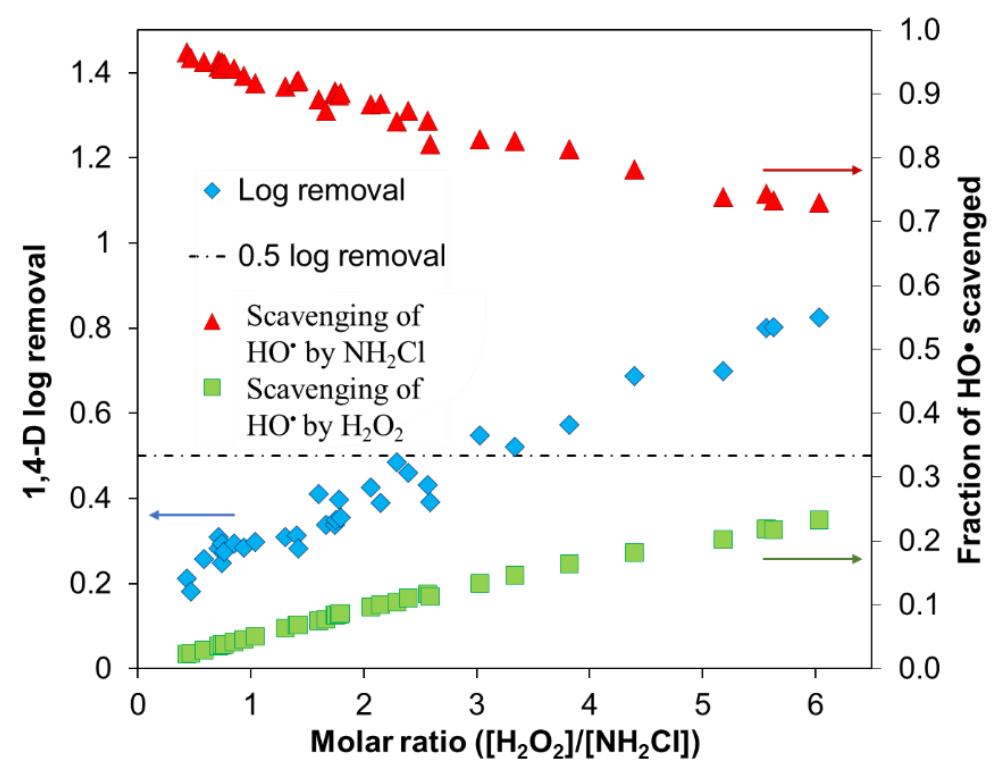

(b)

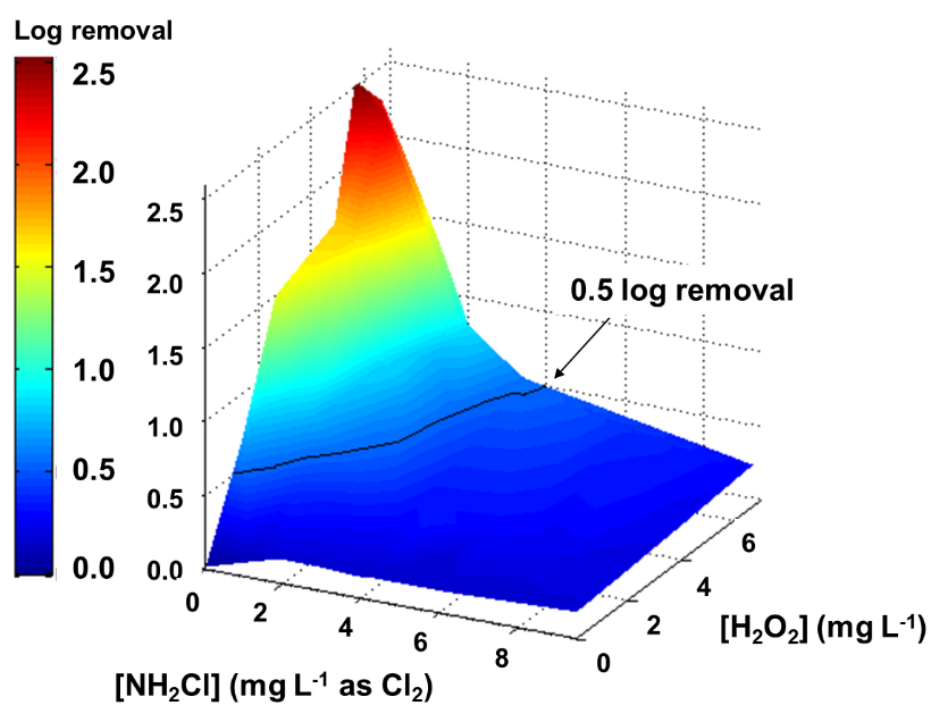

Figure S14. (a) Scatter plot showing log removal and fraction of $\mathrm{HO}^{\bullet}$ scavenged by $\mathrm{NH}_{2} \mathrm{Cl}$ and $\mathrm{H}_{2} \mathrm{O}_{2}$, with increase in molar ratio of $\mathrm{H}_{2} \mathrm{O}_{2}$ to $\mathrm{NH}_{2} \mathrm{Cl}$. (b) Surface plot showing the effect of $\mathrm{H}_{2} \mathrm{O}_{2}(0$ to $6.5 \mathrm{mg}$ $\left.\mathrm{L}^{-1}\right)$ and $\mathrm{NH}_{2} \mathrm{Cl}\left(0.02\right.$ to $\left.9.5 \mathrm{mg} \mathrm{L}^{-1}\right)$ in pilot-scale feed water on the log removal of 1,4-D. Black line represents contour for $0.5 \log$ removal. Experimental conditions: RO permeate; [1,4-D] $=20 \mu \mathrm{g} \mathrm{L}^{-1}$; $\mathrm{pH}=5.8 ;$ total fluence $=850 \pm 50 \mathrm{~mJ} \mathrm{~cm}^{-2}$. 


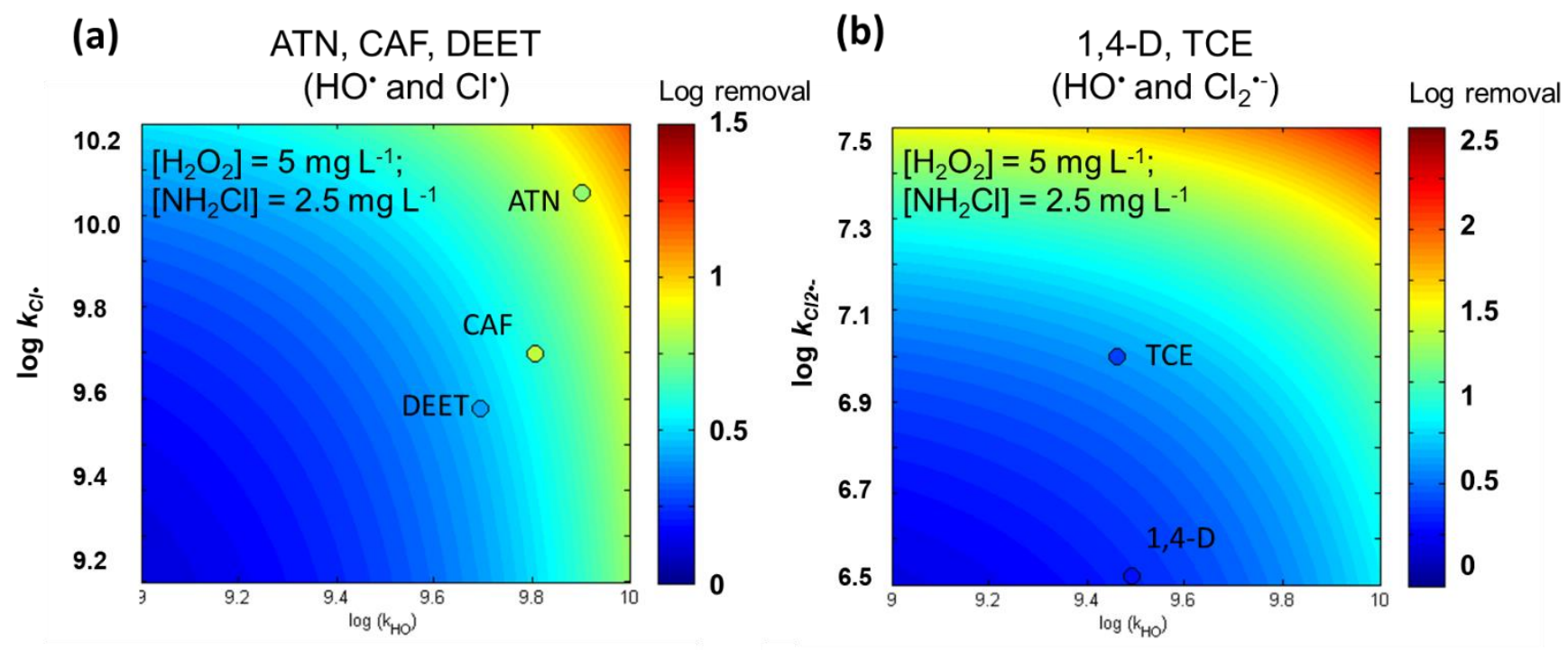

Figure S15. Heat maps showing log removal prediction of trace contaminants (left) contaminants for which $\mathrm{Cl}^{-}$is the primary RCS; (right) contaminants for which $\mathrm{Cl}_{2}{ }^{-}$is the primary RCS. The color in the heat maps depict the predicted log removal of hypothetical contaminant, for which reactivity with $\mathrm{HO}^{\circ}$, and $\mathrm{Cl}^{\bullet}$ or $\mathrm{Cl}_{2}{ }^{-}$is known. The color of the overlying solid circle represents the actual log removal observed of trace contaminants in pilot-scale conditions; the z-axis applies to the heat maps as well as the solid circles. The predictions of log removal are estimated based on methodology described in Text S1. Heat maps are generated using Eq S11a. Values of $\left[\mathrm{HO}^{\bullet}\right]_{\mathrm{ss}}$ and $\left[\mathrm{Cl}^{\bullet}\right]_{\mathrm{ss}}$ are based on Text $\mathrm{S} 1 .\left[\mathrm{Cl}_{2}{ }^{\bullet-}\right]_{\mathrm{ss}}$ was estimated by treating 1,4-D as probe compound. Experimental conditions: [CAF] $=100 \mu \mathrm{g} \mathrm{L}^{-1}$; $\left[\mathrm{NH}_{2} \mathrm{Cl}\right]=2.5 \mathrm{mg} \mathrm{L}^{-1} ;\left[\mathrm{H}_{2} \mathrm{O}_{2}\right]=5 \mathrm{mg} \mathrm{L}^{-1} .[\mathrm{ATN}]=[\mathrm{DEET}]=[1,4-\mathrm{D}]=20 \mu \mathrm{g} \mathrm{L}^{-1} ;[\mathrm{TCE}]=8 \mu \mathrm{g} \mathrm{L}^{-1}$ $\mathrm{pH}=5.8 ;$ total fluence $=850 \pm 50 \mathrm{~mJ} \mathrm{~cm}$. 


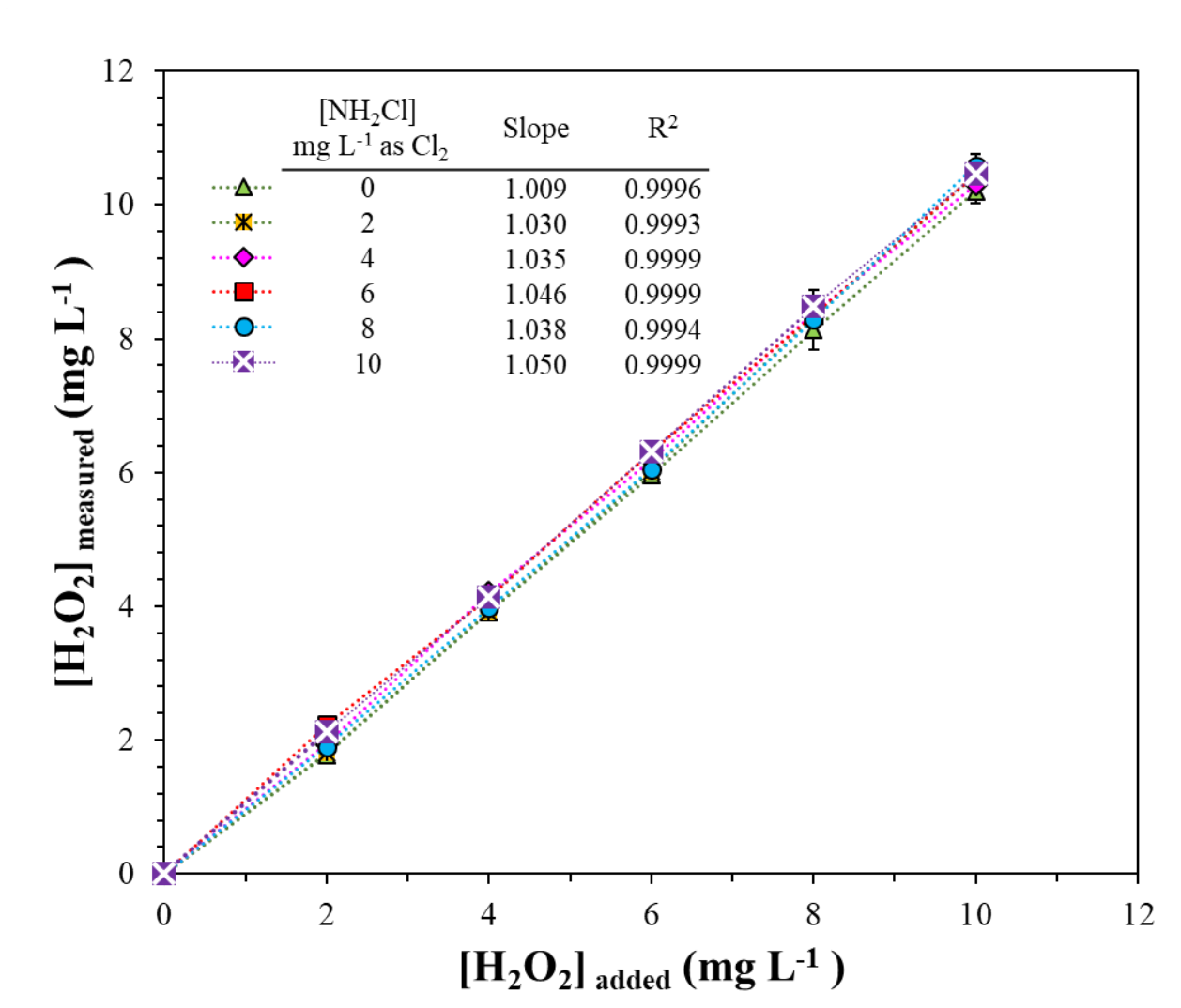

Figure S16. Effect of $\mathrm{NH}_{2} \mathrm{Cl}$ on the concentration of $\mathrm{H}_{2} \mathrm{O}_{2}$ in $\mathrm{RO}$ permeate measured by the titanium oxalate method. For linear regression, y-intercept $=0$. Error bars are $95 \%$ confidence interval from duplicate analysis. Experiments in DI matrix showed similar results. Experimental conditions: pH 5.8; RO permeate; free chlorine $=0 \mathrm{mg} \mathrm{L}^{-1}$ as $\mathrm{Cl}_{2},\left[\mathrm{NH}_{2} \mathrm{CL}\right]=0.5 \mathrm{mg} \mathrm{L}^{-1}$ as $\mathrm{Cl}_{2},\left[\mathrm{NHCl}_{2}\right]=1.9 \mathrm{mg} \mathrm{L}^{-1}$ as $\mathrm{Cl}_{2}$. 


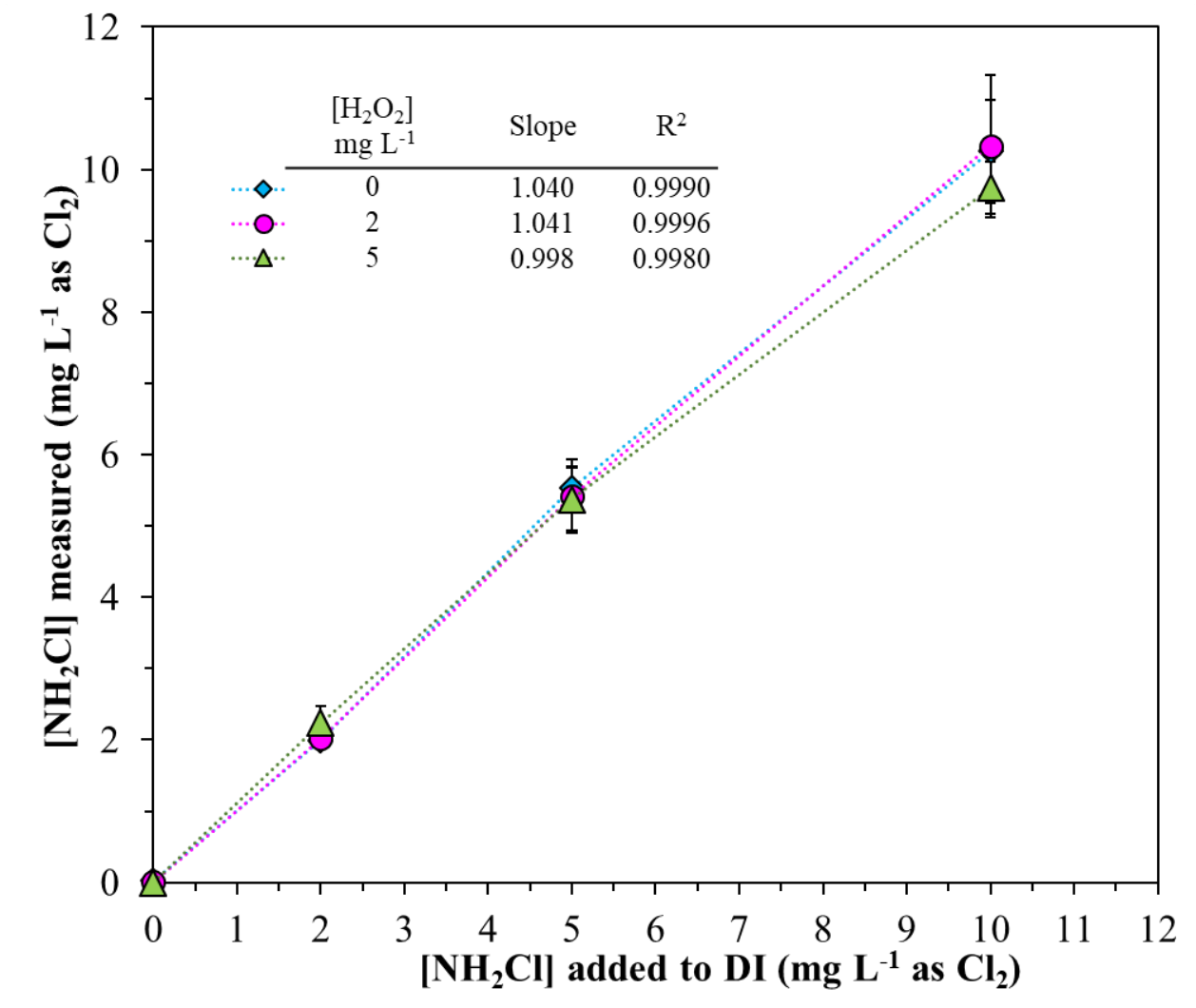

Figure S17. Effect of $\mathrm{H}_{2} \mathrm{O}_{2}$ on $\mathrm{NH}_{2} \mathrm{Cl}$ concentration (as determined by DPD method). No impact of $\mathrm{H}_{2} \mathrm{O}_{2}$ was observed on determination of $\mathrm{NH}_{2} \mathrm{Cl}$. For linear regression, y-intercept $=0$. Error bars are 95\% confidence interval from duplicate analysis. Experimental conditions: DI matrix; $\mathrm{pH} 5.8 ; 40 \mathrm{mM}$ phosphate buffer. 


\section{Text S7. Determination of second-order rate constants for reaction of atenolol and reactive chlorine species}

The second-order rate constants for the reaction of atenolol (ATN) with reactive chlorine species (RCS) was determined based on competition kinetics using probe compounds 1,4-dioxane (1,4-D), BA, and $\mathrm{NB}$ for $\mathrm{HO}^{*}, \mathrm{Cl}^{\bullet}$ and $\mathrm{Cl}_{2}{ }^{\circ-}$ generated during irradiation of $\mathrm{NH}_{2} \mathrm{Cl}$. Experiments were conducted at two concentrations of $\mathrm{NH}_{2} \mathrm{Cl}(2 \mathrm{mM}$ and $4 \mathrm{mM})$. Solutions were prepared with $40 \mathrm{mM}$ phosphate buffer at $\mathrm{pH}$ 5.8, and were spiked with $2.5 \mathrm{mM}$ 1,4-D, $0.5 \mathrm{mM}$ ATN, $0.1 \mathrm{mM}$ BA, and $0.25 \mathrm{mM}$ NB. Approximately $8 \mathrm{~mL}$ of solution was placed in quartz cuvette and placed in a bench-scale UV reactor emitting light at $254 \mathrm{~nm}$. The rate constants of ATN with $\mathrm{Cl}^{\bullet}$ and $\mathrm{Cl}_{2}{ }^{--}$were determined by solving Eq S14 to S17 below:

$\ln \left(\frac{N B}{N B_{O}}\right)_{2 m M}=-k^{\prime \prime}{ }_{N B, H O} \cdot\left[H O^{\bullet}\right]_{S s, 2 m M} t$

Eq S14a

$\ln \left(\frac{N B}{N B_{O}}\right)_{4 m M}=-k^{\prime \prime}{ }_{N B, H O} \cdot\left[H O^{\bullet}\right]_{S s, 4 m M} t$

$\ln \left(\frac{1,4-D}{1,4-D_{o}}\right)_{2 m M}=-k_{1,4 D, H O \bullet}^{\prime \prime}\left[H O^{\bullet}\right]_{s s, 2 m M} t-k^{\prime \prime}{ }_{1,4 D, C l 2 \cdot-}\left[C l_{2}^{\bullet-}\right]_{s s, 2 m M} t$

$\ln \left(\frac{1,4-D}{1,4-D_{o}}\right)_{4 m M}=-k_{1,4 D, H O \cdot}^{\prime \prime}\left[H O^{\bullet}\right]_{S S, 4 m M} t-k^{\prime \prime}{ }_{1,4 D, C l 2 \cdot-}\left[C l_{2}^{\bullet-}\right]_{S S, 4 m M} t$

Eq S15b

$\ln \left(\frac{B A_{o}}{B A}\right)_{2 m M}=-k_{B A, H O}^{\prime \prime}\left[H O^{\bullet}\right]_{S S, 2 m M} t-k_{B A, C l 2 \cdot-}^{\prime \prime}\left[C l_{2}^{\bullet-}\right]_{S S, 2 m M} t-k_{B A, C l \bullet}^{\prime \prime}\left[C l^{\bullet}\right]_{S s, 2 m M} t$

Eq S16a

$\ln \left(\frac{B A_{o}}{B A}\right)_{4 m M}=-k_{B A, H O}^{\prime \prime}\left[H O^{\bullet}\right]_{S S, 4 m M} t-k_{B A, C l 2 \bullet-}^{\prime \prime}\left[C l_{2}^{\bullet-}\right]_{S S, 4 m M} t-k_{B A, C l \bullet}^{\prime \prime}\left[C l^{\bullet}\right]_{S S, 4 m M} t$

Eq S16b 
$\ln \left(\frac{A T N_{O}}{A T N}\right)_{2 m M}=-k_{A T N, H O}^{\prime \prime}\left[H O^{\bullet}\right]_{S S, 2 m M} t-k_{A T N, C l 2 \bullet-}^{\prime \prime}\left[C l_{2}^{\bullet-}\right]_{S S, 2 m M} t-k_{A T M, C l}^{\prime \prime}\left[C l^{\bullet}\right]_{S S, 2 m M} t$

Eq S17a

$\ln \left(\frac{A T N_{O}}{A T N}\right)_{4 m M}=-k_{A T N, H O}^{\prime \prime}\left[H O^{\bullet}\right]_{S S, 4 m M} t-k_{A T N, C l 2 \bullet-}^{\prime \prime}\left[C l_{2}^{\bullet-}\right]_{S S, 2 m M} t-k_{A T M, C l \bullet}^{\prime \prime}\left[C l^{\bullet}\right]_{S S, 4 m M} t$

Eq S17b

Based on these experiments, second order rate constants of $\mathrm{ATN}$ with $\mathrm{Cl}^{\circ}$ and $\mathrm{Cl}_{2}{ }^{--}$were found to be $1.12 \times 10^{10} \mathrm{M}^{-1} \mathrm{~s}^{-1}$ and $9.81 \times 10^{6} \mathrm{M}^{-1} \mathrm{~s}^{-1}$, respectively. Literature-reported rate constants for other indicator compounds in this study are shown in Table S2. 


\section{REFERENCES}

1. Asmus, K.-D.; Cercek, B.; Ebert, M.; Henglein, A.; Wigger, A., Pulse radiolysis of nitrobenzene solutions. Transactions of the Faraday Society 1967, 63, 2435-2441.

2. Cabelli, D. E.; Bielski, B. H., A pulse radiolysis study of some dicarboxylic acids of the citric acid cycle. The kinetics and spectral properties of the free radicals formed by reaction with the $\mathrm{OH}$ radical. Zeitschrift für Naturforschung B 1985, 40, (12), 1731-1737.

3. Neta, P.; Dorfman, L. M., Pulse radiolysis studies. XIII. Rate constants for the reaction of hydroxyl radicals with the aromatic compounds in aqueous solutions. Advanced in Chemistry Series 1968, $81,222-230$.

4. Gilbert, B. C.; Stell, J. K.; Peet, W. J.; Radford, K. J., Generation and reactions of the chlorine atom in aqueous solution. Journal of the Chemical Society, Faraday Transactions 1: Physical Chemistry in Condensed Phases 1988, 84, (10), 3319-3330.

5. Patton, S.; Li, W.; Couch, K. D.; Mezyk, S. P.; Ishida, K. P.; Liu, H., Impact of the ultraviolet photolysis of monochloramine on 1, 4-dioxane removal: New insights into potable water reuse. Environmental Science \& Technology Letters 2016, 4, (1), 26-30.

6. $\quad$ Li, W.; Patton, S.; Gleason, J. M.; Mezyk, S. P.; Ishida, K. P.; Liu, H., UV photolysis of chloramine and persulfate for 1, 4-dioxane removal in reverse-osmosis permeate for potable water reuse. Environmental Science \& Technology 2018, 52, (11), 6417-6425.

7. Patton, S.; Romano, M.; Naddeo, V.; Ishida, K. P.; Liu, H., Photolysis of mono-and dichloramines in UV/hydrogen peroxide: Effects on 1,4-dioxane removal and relevance in water reuse. Environmental Science \& Technology 2018, 52, (20), 11720-11727. 
8. Zhang, K.; Parker, K. M., Halogen Radical Oxidants in Natural and Engineered Aquatic Systems. Environmental Science \& Technology 2018, 52, (17), 9579-9594.

9. Stamps, B. W.; Leddy, M. B.; Plumlee, M. H.; Hasan, N. A.; Colwell, R. R.; Spear, J. R., Characterization of the microbiome at the world's largest potable water reuse facility. Frontiers in Microbiology 2018, 9, 2435.

10. Brodtmann Jr, N. V.; Russo, P. J., The use of chloramine for reduction of trihalomethanes and disinfection of drinking water. Journal-American Water Works Association 1979, 71, (1), 40-42.

11. APHA-AWWA-WEF, Standard Methods for the Examination of Water and Wastewater. 22 ed.; American Public Health Association: Washington DC, 2012.

12. Brandhuber, P. J.; Korshin, G., WRF-04-019: Methods for detection of residual concentrations of hydrogen peroxide in advanced oxidation processes. Water Reuse Foundation: Alexandria, VA, 2009. 13. U.S.EPA, Method 8315A - Determination of carbonyl compounds by high performance liquid chromatography (HPLC) U.S. Environmental Protection Agency: Wahington D.C., 1996.

14. Schneider, S. 5991-1545EN: Analysis of DNPH-derivatized Aldehydes and Ketones using the Agilent 1220 Infinity LC System with Diode Array Detector : Application Notes by Agilent Technologies, Inc. Available at: 〈https://www.agilent.com/cs/library/applications/5991-1023EN.pdf〉. Accessed on: Jan 26, 2018.

15. Glaze, W. C.; Lin, C., Optimization of liquid-liquid extraction methods for analysis of organics in water (EPA/600/4-83/052). US Environmental Protection Agency: Washington D.C., 1983.

16. Hatchard, C.; Parker, C. A., A new sensitive chemical actinometer-II. Potassium ferrioxalate as a standard chemical actinometer. Proceedings of the Royal Society of London 1956, 235, (1203), 518-536. 
17. Eibenberger, J. Pulse radiolytic investigations concerning the formation and the oxidation of organic radicals in aqueous solutions. Vienna University, 1980.

18. Wolfenden, B. S.; Willson, R. L., Radical-cations as reference chromogens in kinetic studies of ono-electron transfer reactions: pulse radiolysis studies of 2, 2'-azinobis-(3-ethylbenzthiazoline-6sulphonate). Journal of the Chemical Society, Perkin Transactions 2 1982, (7), 805-812.

19. Hasegawa, K.; Neta, P., Rate constants and mechanisms of reaction of chloride $\left(\mathrm{Cl}_{2}^{-}\right)$radicals. The Journal of Physical Chemistry 1978, 82, (8), 854-857.

20. Benner, J.; Salhi, E.; Ternes, T.; von Gunten, U., Ozonation of reverse osmosis concentrate: Kinetics and efficiency of beta blocker oxidation. Water Research 2008, 42, (12), 3003-3012.

21. Sun, P.; Lee, W.-N.; Zhang, R.; Huang, C.-H., Degradation of DEET and caffeine under UV/chlorine and simulated sunlight/chlorine conditions. Environmental Science \& Technology 2016, 50, (24), 13265-13273.

22. Song, W.; Cooper, W. J.; Peake, B. M.; Mezyk, S. P.; Nickelsen, M. G.; O'Shea, K. E., Freeradical-induced oxidative and reductive degradation of N, $\mathrm{N}^{\prime}$-diethyl-m-toluamide (DEET): Kinetic studies and degradation pathway. Water Research 2009, 43, (3), 635-642.

23. Getoff, N., Radiation-and photoinduced degradation of pollutants in water. A comparative study. International Journal of Radiation Applications and Instrumentation. Part C. Radiation Physics and Chemistry 1991, 37, (5-6), 673-680.

24. Li, K.; Stefan, M. I.; Crittenden, J. C., Trichloroethene degradation by $\mathrm{UV} / \mathrm{H}_{2} \mathrm{O}_{2}$ advanced oxidation process: Product study and kinetic modeling. Environmental Science \& Technology 2007, 41, (5), 1696-1703. 
25. Li, K.; Stefan, M. I.; Crittenden, J. C., UV photolysis of trichloroethylene: Product study and kinetic modeling. Environmental Science \& Technology 2004, 38, (24), 6685-6693.

26. Gleason, J. M.; McKay, G.; Ishida, K. P.; Mezyk, S. P., Temperature dependence of hydroxyl radical reactions with chloramine species in aqueous solution. Chemosphere 2017, 187, 123-129.

27. Jayson, G.; Parsons, B.; Swallow, A. J., Some simple, highly reactive, inorganic chlorine derivatives in aqueous solution. Their formation using pulses of radiation and their role in the mechanism of the Fricke dosimeter. Journal of the Chemical Society, Faraday Transactions 1: Physical Chemistry in Condensed Phases 1973, 69, 1597-1607.

28. Buxton, G. V.; Greenstock, C. L.; Helman, W. P.; Ross, A. B., Critical review of rate constants for reactions of hydrated electrons, hydrogen atoms and hydroxyl radicals $\left(\cdot \mathrm{OH} / \mathrm{O}^{-}\right)$in aqueous solution. Journal of Physical and Chemical Reference Data 1988, 17, (2), 513-886.

29. Bolton, J. R.; Stefan, M. I., Fundamental photochemical approach to the concepts of fluence (UV dose) and electrical energy efficiency in photochemical degradation reactions. Research on Chemical Intermediates 2002, 28, (7-9), 857-870.

30. Pereira, V. J.; Wienberg, H. S.; Linder, K. G.; Singer, P. C., UV degradation kinetics and modeling of pharmaceutical compounds in laboratory grade and surface water via direct and indirect photolysis at $254 \mathrm{~nm}$. Environmental Science \& Technology 2007, 41, (5), 1682-1688.

31. De Laat, J.; Boudiaf, N.; Dossier-Berne, F., Effect of dissolved oxygen on the photodecomposition of monochloramine and dichloramine in aqueous solution by UV irradiation at $253.7 \mathrm{~nm}$. Water research 2010, 44, (10), 3261-3269.

32. Bircher, K., UV Treatment of RO Permeate for Potable Reuse at the Scottsdale Water Factory. IUVA News 2017, 19, (4). 